\title{
3,3'-Diindolylmethane (DIM) and its ring-substituted halogenated analogs (ring-DIMs) induce differential mechanisms of survival and death in androgen-dependent and -independent prostate cancer cells
}

\author{
Alexander A. Goldberg ${ }^{1,2, *}$, Hossam Draz ${ }^{1,3, *}$, Diana Montes-Grajales ${ }^{4}$, Jesus \\ Olivero-Verbél ${ }^{4}$, Stephen H. Safe ${ }^{5}$ and J. Thomas Sanderson ${ }^{1}$ \\ 1 INRS-Institut Armand-Frappier, Laval, Québec, Canada \\ ${ }^{2}$ Critical Care Division and Meakins-Christie Laboratories, Faculty of Medicine, McGill University, Montreal, Quebec H3A 1A1, \\ Canada \\ ${ }^{3}$ Department of Biochemistry, National Research Centre, Dokki, Cairo, Egypt \\ ${ }^{4}$ Environmental and Computational Chemistry Group, University of Cartagena, Colombia \\ ${ }^{5}$ Veterinary Physiology and Pharmacology, Texas A\&M University, College Station, TX, United States \\ * These authors have contributed equally to this work \\ Correspondence to: J. Thomas Sanderson, email: thomas.sanderson@iaf.inrs.ca \\ Keywords: prostate cancer, LNCaP, C42B, DU145, mitochondrial function \\ Received: January 29, $2015 \quad$ Accepted: April 16, 2015 \\ Published: April 26, 2015
}

This is an open-access article distributed under the terms of the Creative Commons Attribution License, which permits unrestricted use, distribution, and reproduction in any medium, provided the original author and source are credited.

\section{ABSTRACT}

We recently reported that novel ring-substituted analogs of 3,3'-diindolylmethane (ring-DIMs) induce apoptosis and necrosis in androgen-dependent and -independent prostate cancer cells. In this paper, we have focused on the mechanism(s) associated with ring-DIM-mediated cell death, and on identifying the specific intracellular target(s) of these compounds. The 4,4'- and 7,7'-dichloroDIMs and 4,4'- and 7,7'-dibromoDIMs induced the death of LNCaP, C42B and DU145 prostate cancer cells, but not that of immortalized normal human prostate epithelial (RWPE-1) cells. RingDIMs caused the early loss of mitochondrial membrane potential (MMP) and decreased mitochondrial ATP generation in prostate cancer cells. Cyclosporin A, an inhibitor of the mitochondrial permeability transition pore, inhibited ring-DIM-mediated cell death, and salubrinal, an inhibitor of ER stress, inhibited cell death mediated only by 4,4'-dihaloDIMs. We found that although salubrinal did not inhibit the onset of ER stress, it prevented 4,4'-dibromoDIM mediated loss of MMP. Salubrinal potentiated cell death in response to 7,7'-dihaloDIMs and DIM, and this effect concurred with increased loss of MMP. Using in silico 3-D docking affinity analysis, we identified $\mathrm{Ca}^{2+}$ / calmodulin-dependent kinase II (CaMKII) as a potential direct target for the most toxic ring-DIM, 4,4'-dibromoDIM. An inhibitor of CaMKII, KN93, but not its inactive analog KN92, abrogated cell death mediated by 4,4'-dibromoDIM. The ring-DIMs induced ER stress and autophagy, but these processes were not necessary for ring-DIM-mediated cell death. Inhibition of autophagy with bafilomycin A1, 3-methyladenine or by LC3B gene silencing sensitized LNCaP and C42B, but not ATG5-deficient DU145 cells to ring-DIM- and DIM-mediated cell death. We propose that autophagy induced by the ring-DIMs and DIM has a cytoprotective function in prostate cancer cells. 


\section{INTRODUCTION}

Prostate cancer accounts for almost one third of all cancer deaths in the United States and is the second highest cause of cancer-related death in males [1]. Most prostate tumours are initially androgen-dependent (AD). However, a large contingent will progress to an aggressive androgenindependent (AI) form, which are more drug-resistant and lead to increased morbidity and mortality among patients. Currently, prostate cancer is treated with a combination of radiotherapy, chemical castration, androgen receptor (AR) antagonists (hydroxyflutamide, bicalutamide), or inhibitors of steroidogenesis (abiraterone). Patients treated with hydroxyflutamide or bicalutamide often suffer from severe side-effects as a result of the anti-androgenic therapy [2, $3]$, necessitating the search for novel chemotherapeutic agents with fewer deleterious effects. Moreover, it is imperative to search for novel therapeutic targets which may aid the development of a new generation of drugs effective in the elimination of AI prostate tumours.

3,3'-Diindolylmethane (DIM) is a natural small molecule produced in the stomach after ingestion of vegetables of the Brassica family containing high amounts of indole-3-carbinol (I3C). I3C is converted via acidcatalyzed reactions in the stomach to various condensation products, of which DIM is considered its most biologically active metabolite [4, 5]. DIM has been studied extensively as an anticancer agent due to its ability to inhibit the growth of a multitude of cancer cell types in vitro and in vivo $[6,7]$ and has produced positive responses in clinical trials for the treatment of prostate cancer when applied in an absorption-enhanced formulation [8]. DIM affects a number of distinct yet overlapping pathways, leading to the inhibition of cancer cell proliferation. For example, DIM down-regulates AR transcriptional activity, thereby reducing AR-mediated gene expression [9-12]. DIM also inhibits pro-survival cell signaling pathways such as phosphatidylinositide 3-kinase (PI3K), Akt, mammalian target of rapamycin (mTOR) and c-Met, and also activates pro-apoptotic pathways such as Hippo and glycogen synthase kinase 3-beta (GSK-3 $\beta$ ), resulting in inhibition of cancer cell proliferation [13-19]. DIM activates the pro-apoptotic proteins Fas, FasL and death receptor 5 (DR5), leading to caspase-dependent apoptosis [7, 9, 17, 20]. DIM also increases the intracellular flux of calcium ions, resulting in the induction of endoplasmic reticulum (ER) stress genes [21-23], in addition to decreasing mitochondrial function through inhibition of ATP synthase [24-26], which in turn induces AMP-activated protein kinase-(AMPK)-dependent autophagy [27]. DIM also exerts effects on DNA methyltranferases, resulting in modified methylation patterns of genes involved in inflammation, cell signaling, cell motility and apoptosis [28]. However, the specific molecular targets that directly interact with DIM to cause ER stress, mitochondrial dysfunction, autophagy, and ultimately cell death have yet to be discerned.

We have previously shown that several halogenated analogs of DIM, termed ring-DIMs, act as anti-androgenic compounds that inhibit $\mathrm{AD}$ proliferation of $\mathrm{LNCaP}$ human prostate cancer cells and induce apoptosis and necrosis of $\mathrm{AD}$ as well as $\mathrm{AI}$ prostate cancer cells with greater potencies than DIM $[11,17]$. Cell death induced only by the most potent ring-DIM, 4,4'-Br ${ }_{2} \mathrm{DIM}$, was partially dependent on activation of caspase-3, which occurred concomitant with increases in Fas, FasL, DR4 and DR5 expression. The objective of the present study was to determine the early events that ultimately result in cell death induced by 4,4'- and 7,7'-dibromo- and dichloro-substituted ring-DIMs and DIM by determining their concentration- and time-dependent effects on mitochondrial stability, ER stress and autophagy. We also performed an in silico docking affinity analysis to identify proteins that could potentially interact with ring-DIMs and DIM.

\section{RESULTS}

\section{Ring-DIMs kill LNCaP, C42B and DU145 prostate cancer cells, but not RWPE-1 immortalized normal prostate epithelial cells}

We tested the ability of the ring-DIMs to kill prostate cancer cells that express a DHT-responsive AR (LNCaP), a constitutively active AR (C42B) and cells lacking AR (DU145). In LNCaP and C42B cells, 4,4'- $\mathrm{Br}_{2} \mathrm{DIM}\left(\mathrm{IC}_{50}\right.$ $=13.1 \mu \mathrm{M}, 16.7 \mu \mathrm{M}$, respectively), 4,4'- $\mathrm{Cl}_{2} \mathrm{DIM}\left(\mathrm{IC}_{50}\right.$ $=20.2 \mu \mathrm{M}, 29.3), 7,7^{\prime}-\mathrm{Br}_{2} \mathrm{DIM}\left(\mathrm{IC}_{50}=19.5 \mu \mathrm{M}, 25.3\right.$ $\mu \mathrm{M})$ and $7,7^{\prime}-\mathrm{Cl}_{2} \mathrm{DIM}\left(\mathrm{IC}_{50}=15.8 \mu \mathrm{M}, 25.7 \mu \mathrm{M}\right)$ were all significantly more potent at killing cells than DIM $\left(\mathrm{IC}_{50}\right.$ $=23.3,46.1 \mu \mathrm{M}$ ), (Fig. 1A, B). The most cytotoxic ringDIM, 4,4'-Br ${ }_{2}$ DIM, killed AR-negative DU145 cells with the same potency as $\mathrm{C} 42 \mathrm{~B}$ cells with an $\mathrm{IC}_{50}$ of $20 \mu \mathrm{M}$ (Supplementary Fig. S1A). At concentrations that were toxic to the prostate cancer cells neither the ring-DIMs nor DIM induced cell death in RWPE-1 cells (Fig. 1C).

\section{Mitochondrial dysfunction and ER stress are early events in ring-DIM induced cell death}

To further investigate the mechanism of ring-DIMinduced toxicity, we looked at MMP, mitochondrial ATP generation and ER stress in response to ringDIM exposure. After only 1 hour of exposure to the 4,4'-dihaloDIMs, MMP decreased by $36-40 \%$ in $\mathrm{LNCaP}$ and $54-60 \%$ in C42B cells, whereas MMP decreased by only $30 \%$ in $\mathrm{LNCaP}$ and $36 \%$ in C42B cells after a 1 hour treatment with DIM. The 7,7'-dihaloDIMs (Fig. 2A, B) decreased MMP by only $15-18 \%$ in LNCaP and 16$24 \%$ in C42B cells. The observed decreases in MMP were 
Table 1: Docking affinities ( $\mathrm{kcal} / \mathrm{mol})$ of DIM and its derivatives for the four isoforms of the calmodulin-dependent kinase II protein involved in mitochondrial metabolism and signaling pathways.

\begin{tabular}{|c|c|c|c|c|c|c|c|}
\hline \multirow[t]{2}{*}{ Short name } & \multirow[t]{2}{*}{ Pathway } & \multirow[t]{2}{*}{ PDB ID } & \multicolumn{5}{|c|}{ Docking affinity (kcal/mol) } \\
\hline & & & $\begin{array}{l}\text { 4,4'-dibromo } \\
\text { DIM }\end{array}$ & $\begin{array}{l}\text { 4,4'dichloro } \\
\text { DIM }\end{array}$ & $\begin{array}{l}\text { 7,7'-dibromo } \\
\text { DIM }\end{array}$ & $\begin{array}{l}\text { 7,7'-dichloro } \\
\text { DIM }\end{array}$ & $\begin{array}{l}\text { diindolylmethane } \\
\text { (DIM) }\end{array}$ \\
\hline $\begin{array}{l}\text { CaMK-II } \\
\text { subunit } \alpha\end{array}$ & $\begin{array}{l}\text { Signal } \\
\text { transduction }\end{array}$ & 2VZ6/Q9UQM7 & $-8.8 \pm 0.0$ & $-9.0 \pm 0.0$ & $-8.8 \pm 0.1$ & $-8.9 \pm 0.1$ & $-9.2 \pm 0.0$ \\
\hline $\begin{array}{l}\text { CaMK-II } \\
\text { subunit } \beta\end{array}$ & $\begin{array}{l}\text { Signal } \\
\text { transduction }\end{array}$ & 3BHH/Q13554 & $-9.5 \pm 0.0$ & $-9.5 \pm 0.0$ & $-9.0 \pm 0.0$ & $-8.9 \pm 0.1$ & $-9.1 \pm 0.0$ \\
\hline $\begin{array}{l}\text { CaMK-II } \\
\text { subunit } \gamma\end{array}$ & $\begin{array}{l}\text { Signal } \\
\text { transduction }\end{array}$ & 2V7O/Q13555 & $-8.9 \pm 0.1$ & $-9.1 \pm 0.0$ & $-9.1 \pm 0.7$ & $-8.6 \pm 0.8$ & $-9.2 \pm 0.1$ \\
\hline $\begin{array}{l}\text { CaMK-II } \\
\text { subunit } \delta\end{array}$ & $\begin{array}{l}\text { Signal } \\
\text { transduction }\end{array}$ & 2WEL/Q13557 & $-7.4 \pm 0.0$ & $-7.6 \pm 0.0$ & $-7.4 \pm 0.1$ & $-7.7 \pm 0.1$ & $-7.5 \pm 0.0$ \\
\hline
\end{tabular}

sustained for at least 8 hours. DIM and all ring-DIMs, except $7,7^{\prime}-\mathrm{Br}_{2} \mathrm{DIM}$, significantly decreased mitochondrial ATP generation in both cell lines by up to $80 \%$ (Fig. 2C, D). In DU145 cells treated with 4,4-Br ${ }_{2}$ DIM, we observed decreases in MMP by $63 \%$ and ATP generation by $45 \%$ compared to controls (Supplementary Fig. S1B, C).

Treatment of $\mathrm{LNCaP}$ and $\mathrm{C} 42 \mathrm{~B}$ cells with 4,4'- $\mathrm{Br}_{2} \mathrm{DIM}, 7,7^{\prime}-\mathrm{Cl}_{2} \mathrm{DIM}$ or DIM also caused a significant increase in the levels of expression of ER stressrelated proteins $\mathrm{CHOP}$ and $\mathrm{ATF} 4$ and the phosporylation of eIF $2 \alpha$ between 1 and 8 hours of exposure (Fig. 2E, F). These results were also observed in DU145 cells using 4,4-Br ${ }_{2} \mathrm{DIM}$, which also increased ATF4 and CHOP levels after treatment for 1 to 8 hours (Supplementary Fig. S1D).

\section{Ring-DIM-induced cell death is dependent on mitochondrial dysfunction}

We next assessed whether CsA, an inhibitor of the mitochondrial permeability transition pore, could abrogate the toxicity of cells exposed to the ring-DIMs or DIM. We found that pre-treatment with $5 \mu \mathrm{M}$ of CsA prevented ring-DIM-mediated loss of cell viability, but did not affect DIM-induced death of $\mathrm{LNCaP}$ or $\mathrm{C} 42 \mathrm{~B}$ cells (Fig. 3A, B). In LNCaP and C42B cells, CsA prevented the loss of MMP caused by the 4,4'-dihaloDIMs and, to a lesser extent, DIM, but had no effect on the loss of MMP mediated by the 7,7'-dihaloDIMs (Fig. 3C, D). We confirmed that CsA also prevented 4,4'- $\mathrm{Br}_{2} \mathrm{DIM}$ mediated cell death and loss of MMP in AI DU145 cells (Supplementary Fig. S1E and B). However, CsA had no effect on the phosphorylation status of eIF2 $\alpha$ or the expression levels of CHOP and ATF4 in LNCaP or C42B cells treated with either of the three compounds (Fig. 3E$\mathrm{G})$; this was confirmed using only 4,4'- $\mathrm{Br}_{2} \mathrm{DIM}$ in DU145 cells (Supplementary Fig. S1F). Treatment with CsA alone did not affect cell viability or eIF2 $\alpha$ phosphorylation in LNCaP, C42B or DU145 cells (Supplementary Fig. S2A, B); nor did it significantly affect MMP (Supplementary Fig. S2C).
A LNCaP

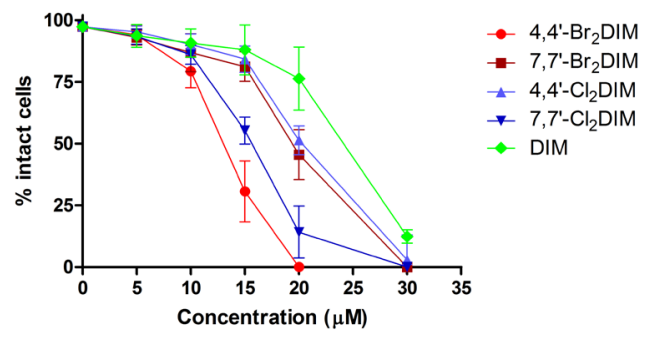

B $\quad$ C42B

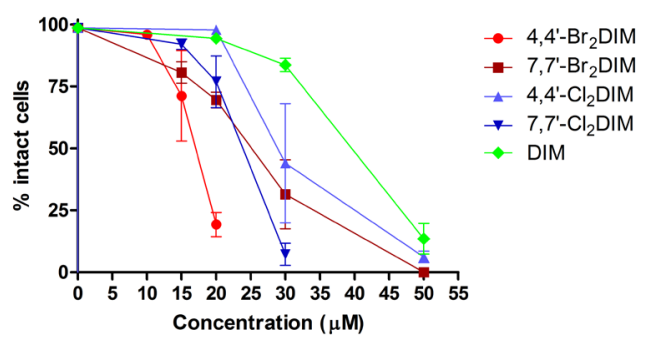

C RWPE-1

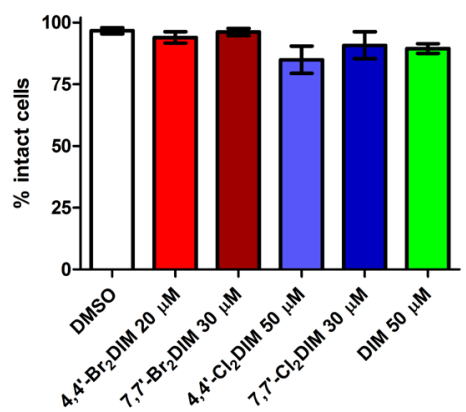

Figure 1: Ring-DIMs kill LNCaP and C42B prostate cancer cells, but not RPWE-1 immortalized normal prostate epithelial cells. The percentage of intact $\mathrm{LNCaP}$ (A) and C42B (B) cells that do not have fragmented nuclei, condensed chromatin or propidium iodide staining was determined after a 24 hour exposure to increasing concentrations of $4,4^{\prime}-\mathrm{Br}_{2} \mathrm{DIM}, 7,7^{\prime}-\mathrm{Br}_{2} \mathrm{DIM}, 4,4^{\prime}-\mathrm{Cl}_{2} \mathrm{DIM}, 7,7^{\prime}-\mathrm{Cl}_{2} \mathrm{DIM}$ or DIM. (C) Percentage of intact RWPE-1 cells after a 48 hour exposure to the ring-DIMs or DIM. 


\section{Salubrinal inhibits cell death and loss of MMP but not $E R$ stress mediated by 4,4 '- $\mathrm{Br}_{2} \mathrm{DIM}$}

Salubrinal is an inhibitor of ER stress that blocks dephosphorylation of eIF $2 \alpha$, and we investigated the effects of this compound on the cytotoxicity of the ringDIMs and DIM. Pre-treatment of LNCaP and C42B cells with $20 \mu \mathrm{M}$ of salubrinal inhibited cell death caused by 4,4'-dihaloDIMs, but not 7,7'-dihaloDIMs or DIM (Fig 4A, B); in DU145 cells salubrinal pre-treatment also completely prevented $4,4^{\prime}-\mathrm{Br}_{2} \mathrm{DIM}$-induced cell death (Supplementary Fig. S1E).

In cells exposed to $4,4^{\prime}-\mathrm{Br}_{2} \mathrm{DIM}$ or $4,4^{\prime}-\mathrm{Cl}_{2} \mathrm{DIM}$, pre-treatment with salubrinal attenuated the 4,4'-dihaloDIM-mediated decrease in MMP (Fig 4C, D) (Supplementary Fig. S1B). Salubrinal pre-treatment alone did not significantly affect MMP in LNCaP, C42B or DU145 cells (Supplementary Fig. S2C). Using the most toxic of the 4,4'-dihaloDIMs as prototype, the $4,4^{\prime}-\mathrm{Br}_{2}$ DIM-mediated increase in phosphorylation of eIF2 $\alpha$ was inhibited by pre-treatment with salubrinal in all three cell lines (Fig. 4E and Supplementary Fig. S1G). However, in LNCaP and C42B cells, pre-treatment with salubrinal did not consistently abrogate the 4,4'- $\mathrm{Br}_{2} \mathrm{DIM}$ induced levels of CHOP or ATF4 (Fig. 4E), and in DU145 cells salubrinal only partially reduced the $4,4^{\prime}-\mathrm{Br}_{2} \mathrm{DIM}$ induced expression of these markers of ER stress (Supplementary Figure S1G). Salubrinal alone did not affect cell viability or eIF $2 \alpha$ phosphorylation in either of the three cell lines (Supplementary Figure S2A, B).

\section{Salubrinal potentiates 7,7'-dihaloDIM- and DIM- mediated toxicity via loss of MMP}

Next, we asked if salubrinal could sensitize prostate cancer cells to cell death induced by the 7,7'-dihaloDIMs and DIM. Pre-treatment of LNCaP and C42B cells with salubrinal enhanced the loss of cell viability caused by concentrations of the 7,7'-dihaloDIMs or DIM that are otherwise sub-toxic (defined as all cells being intact and not visibly Hoechst- or PI-stained) in cells that are exposed to the 7,7'-dihaloDIMs alone. Loss of viability mediated by co-treatment of $\mathrm{LNCaP}$ or $\mathrm{C} 42 \mathrm{~B}$ cells with salubrinal and sub-toxic concentrations of 7,7'-dihaloDIMs was attenuated by pre-treatment with CsA (Fig. 5A, B). Consistent with the lack of abrogation of the cytotoxicity
A

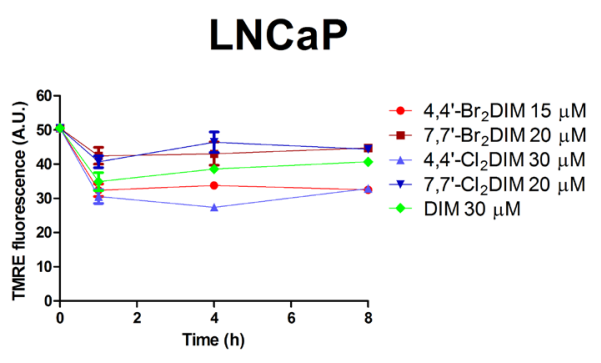

B

C42B

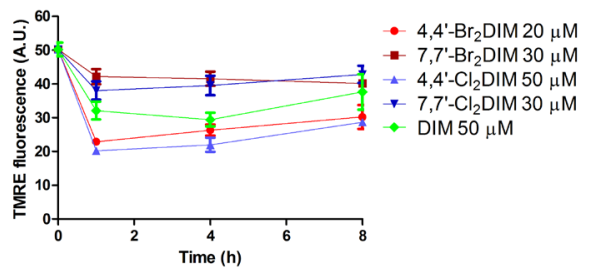

C

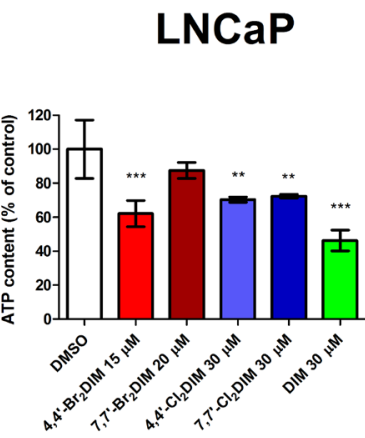

D

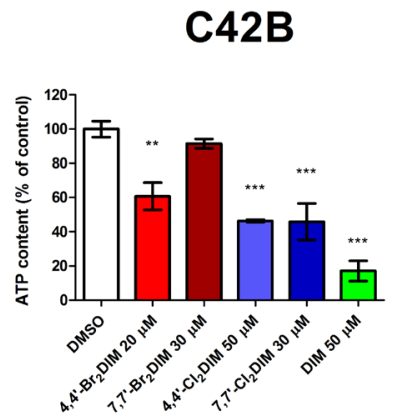

E

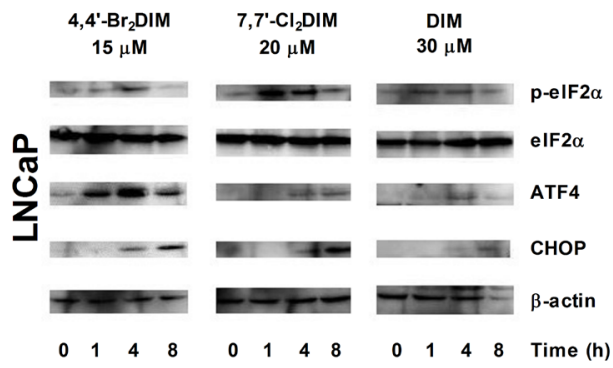

$\mathbf{F}$

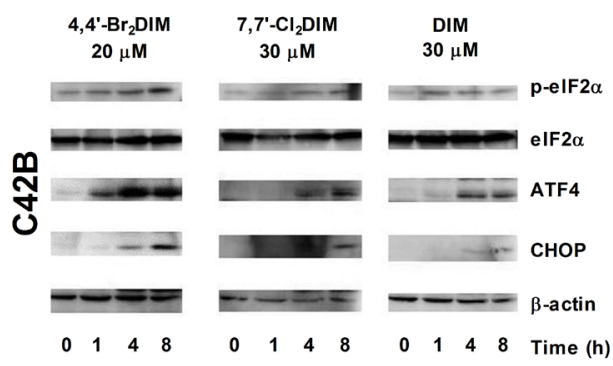

Figure 2: Mitochondrial dysfunction and ER stress are early events in ring-DIM- and DIM-mediated prostate cancer cell death. Tetramethylrhodamine ethyl ester (TMRE) fluorescence of LNCaP (A) and C42B (B) cells after 0, 1, 4, and 8 hrs of exposure to 4,4'- $\mathrm{Br}_{2} \mathrm{DIM}, 7,7^{\prime}-\mathrm{Br}_{2} \mathrm{DIM}, 4,4^{\prime}-\mathrm{Cl}_{2} \mathrm{DIM}, 7,7^{\prime}-\mathrm{Cl}_{2} \mathrm{DIM}$ or DIM. Relative mitochondrial ATP levels of LNCaP (C) and C42B (D) cells treated with $5 \mathrm{mM}$ 2-deoxy-D-glucose after a 1 h exposure to 4,4'-Br $\mathrm{DIM}, 7,7^{\prime}-\mathrm{Br}_{2} \mathrm{DIM}, 4,4^{\prime}-\mathrm{Cl}_{2} \mathrm{DIM}, 7^{2}, 7^{\prime}-\mathrm{Cl}_{2} \mathrm{DIM}$ or DIM. Phosphorylation of eIF $2 \alpha$, and levels of ER stress proteins were assayed by immunoblot of LNCaP (E) and C42B (F) cells after 0 , 1, 4, and $8 \mathrm{hrs}$ of exposure to $4,4^{\prime}-\mathrm{Br}_{2} \mathrm{DIM}, 7,7^{\prime}-\mathrm{Cl}_{2} \mathrm{DIM}$ or DIM. 

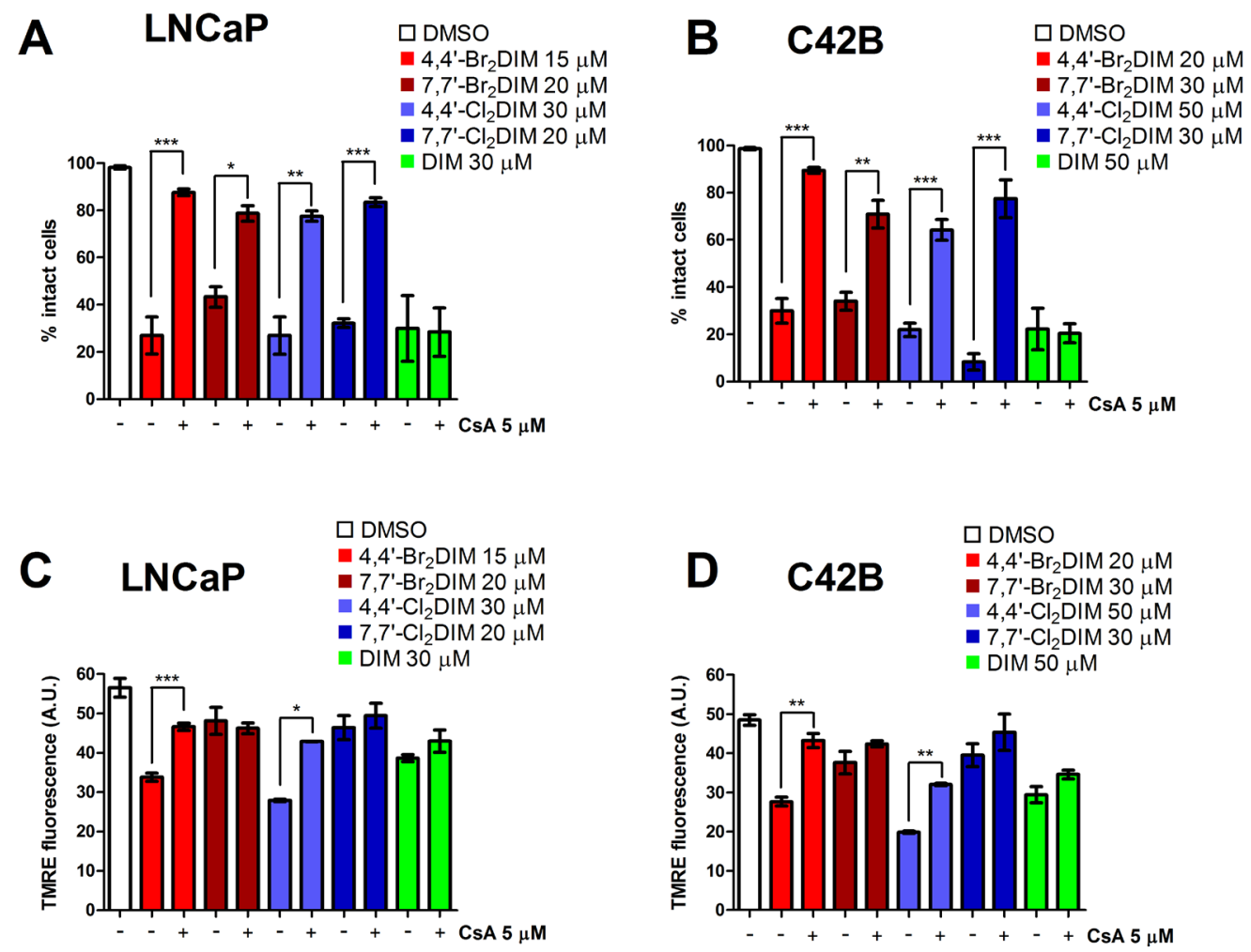

E
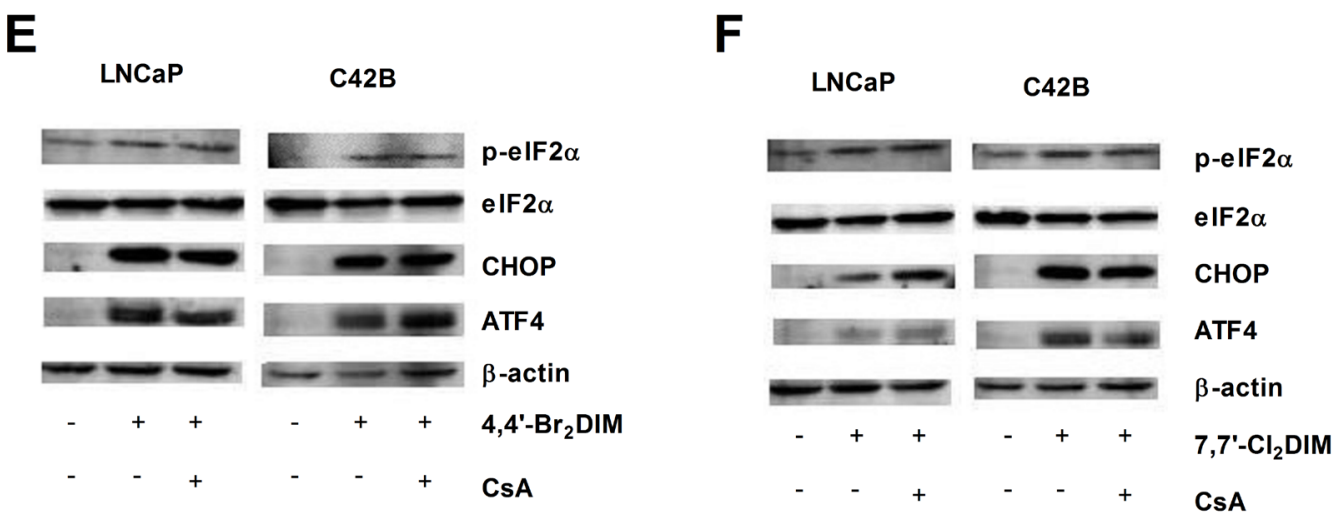

$\mathbf{G}$

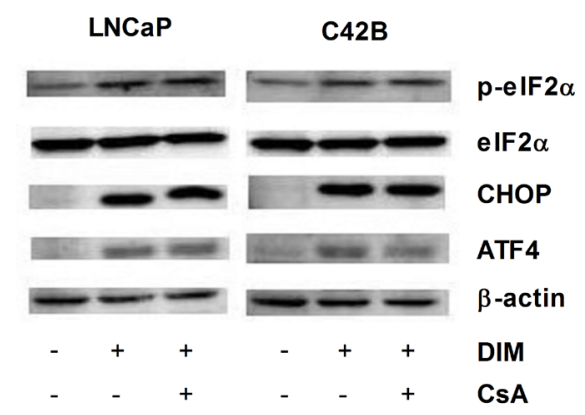

Figure 3: Ring-DIM mediated cell death is dependent on the mitochondrial permeability transition pore (mPTP). Percentage of intact LNCaP (A) and C42B (B) cells after a 24 h exposure to 4,4'- $\mathrm{Br}_{2} \mathrm{DIM}, 7,7^{\prime}-\mathrm{Br}_{2} \mathrm{DIM}, 4,4^{\prime}-\mathrm{Cl}_{2} \mathrm{DIM}, 7,7^{\prime}-\mathrm{Cl}_{2} \mathrm{DIM}$, or DIM with or without a $4 \mathrm{~h}$ pre-treatment with cyclosporin A (CsA). TMRE fluorescence of LNCaP (C) or C42B (D) cells after a $4 \mathrm{~h}$ exposure to 4,4'-Br ${ }_{2} \mathrm{DIM}, 7,7^{\prime}-\mathrm{Br}_{2} \mathrm{DIM}, 4,4^{\prime}-\mathrm{Cl}_{2} \mathrm{DIM}, 7,7^{\prime}-\mathrm{Cl}_{2} \mathrm{DIM}$, or DIM with or without a $4 \mathrm{~h}$ pre-treatment with cyclosporin $\mathrm{A}$ (CsA). Phosphorylation of eIF $2 \alpha$, and levels of ER stress proteins in $\mathrm{LNCaP}$ and C42B cell extracts after a 24 hour exposure to 4,4 ' $-\mathrm{Br}_{2} \mathrm{DIM}$ (E), $7,7^{\prime}-\mathrm{Cl}_{2}$ DIM (F) or DIM (G) with or without a 4 hour pre-treatment with CsA. 
of DIM by CsA alone (Fig 3A,B) CsA was also incapable of abrogating the cytotoxicity of DIM that was potentiated by pre-treatment with salubrinal (Fig. 5A, B)

LNCaP and $\mathrm{C} 42 \mathrm{~B}$ cells pre-treated with salubrinal and treated with either $7,7^{\prime}-\mathrm{Br}_{2} \mathrm{DIM}, 7,7^{\prime}-\mathrm{Cl}_{2} \mathrm{DIM}$ or DIM, exhibited a sharp decrease in MMP after 4 hours (Fig. 5C, D). Combined pre-treatment of cells with salubrinal and CsA partially or fully restored the loss of MMP caused by 7,7'-Cl ${ }_{2}$ DIM, 7,7'-Br 2 DIM and DIM (Fig 5C, D). Neither salubrinal nor combined salubrinal and CsA pre-treatments affected eIF $2 \alpha$ phosphorylation in response to sub-toxic concentrations of 7,7'-dihaloDIMs or DIM as determined in C42B cells (Fig. 5E).

\section{Ring-DIMs and DIM induce protective autophagy in prostate cancer cells}

We investigated the potential of DIM and the ringDIMs to induce autophagy in prostate cancer cells. A dose-
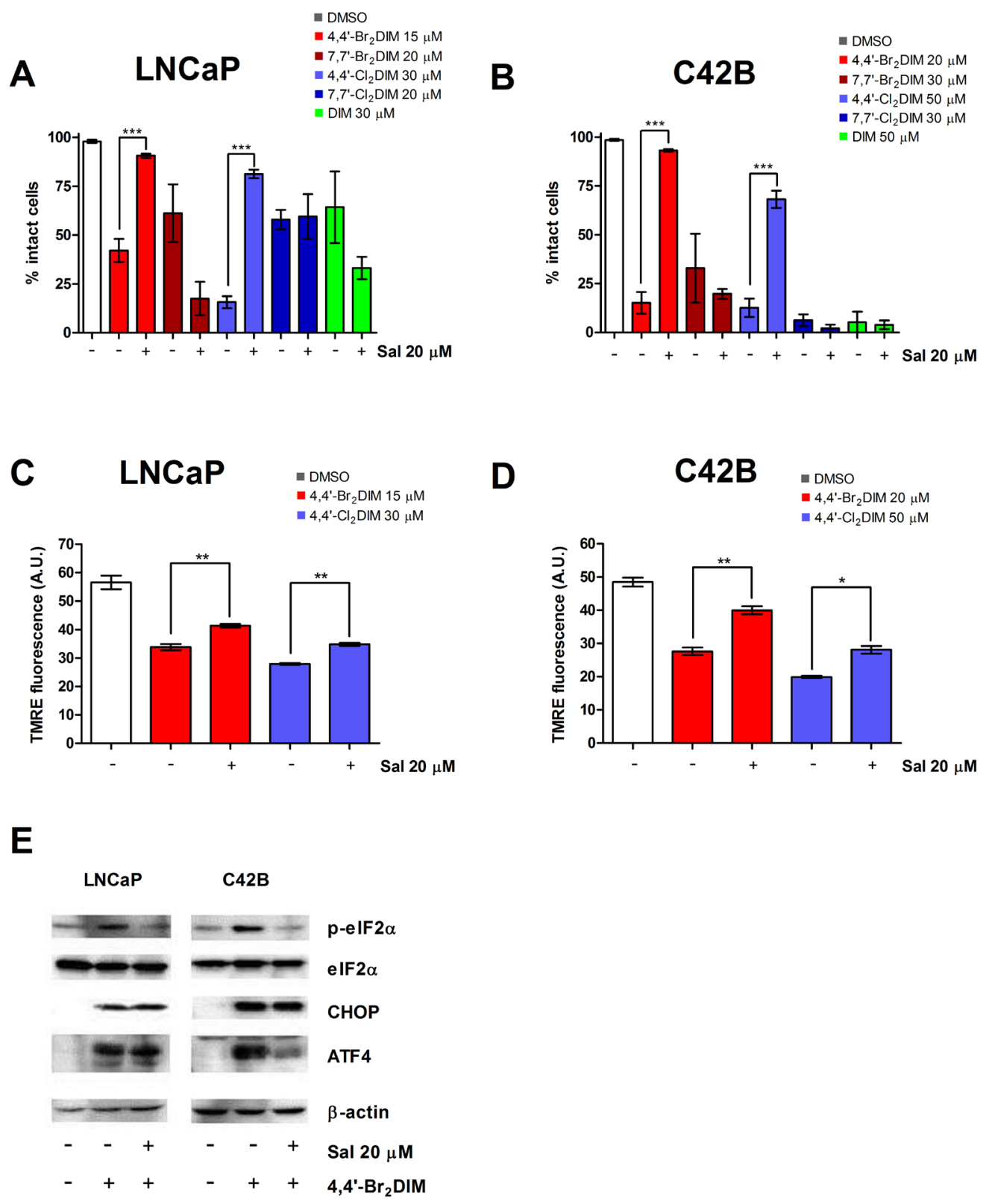

Figure 4: Salubrinal modulates mitochondrial activity in prostate cancer cells treated with 4,4'-dihaloDIMs. The percentage of intact $\mathrm{LNCaP}$ (A) and $\mathrm{C} 42 \mathrm{~B}$ (B) cells was calculated after a 24 hour exposure to toxic concentrations of 4,4'- $\mathrm{Br}_{2} \mathrm{DIM}$, 7,7'- $\mathrm{Br}_{2} \mathrm{DIM}, 4,4^{\prime}-\mathrm{Cl}_{2} \mathrm{DIM}, 7,7^{\prime}-\mathrm{Cl}_{2} \mathrm{DIM}$, DIM with or without a $4 \mathrm{~h}$ pre-treatment with salubrinal. TMRE fluorescence of LNCaP (C) and C42B (D) cells after a 4 hour exposure to $4,4^{\prime}-\mathrm{Br}_{2} \mathrm{DIM}$ or $4,4^{\prime}-\mathrm{Cl}_{2} \mathrm{DIM}$ with or without a $4 \mathrm{~h}$ pre-treatment with salubrinal. (E) Phosphorylation of eIF $2 \alpha$, and levels of ER stress proteins after a 24 hour exposure to 4,4 '- $\mathrm{Br}_{2} \mathrm{DIM}$ with or without a 4 hour pre-treatment with salubrinal. 
A LNCaP

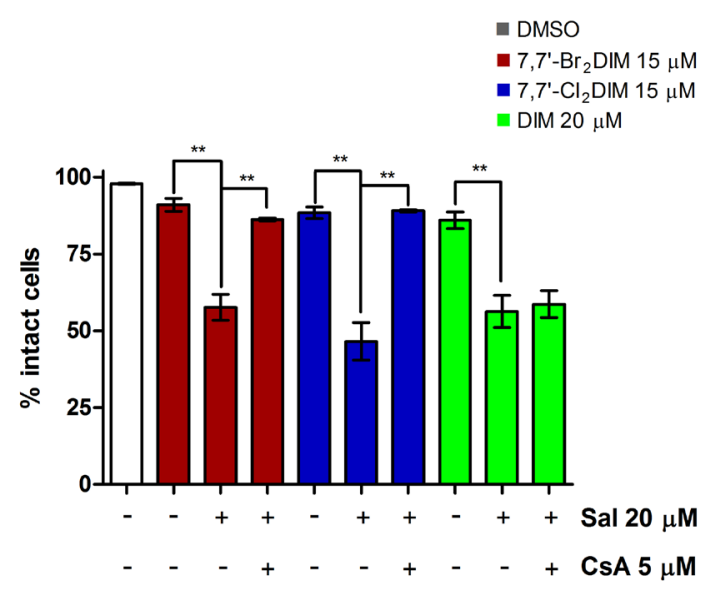

C LNCaP

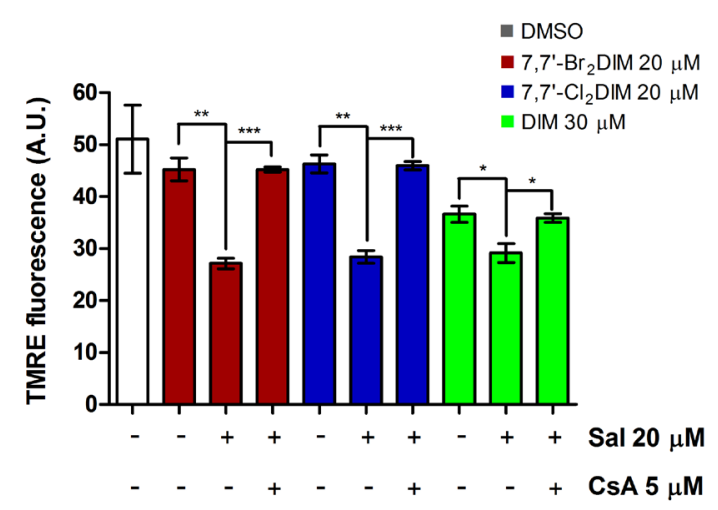

B C42B

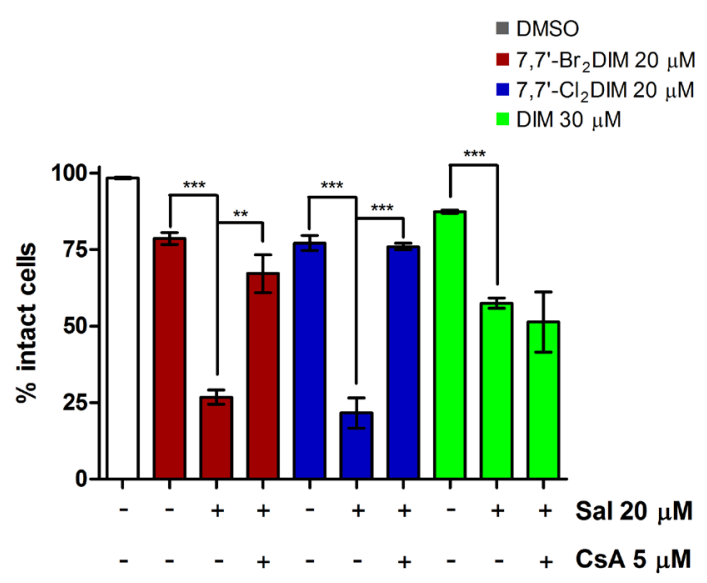

D C42B

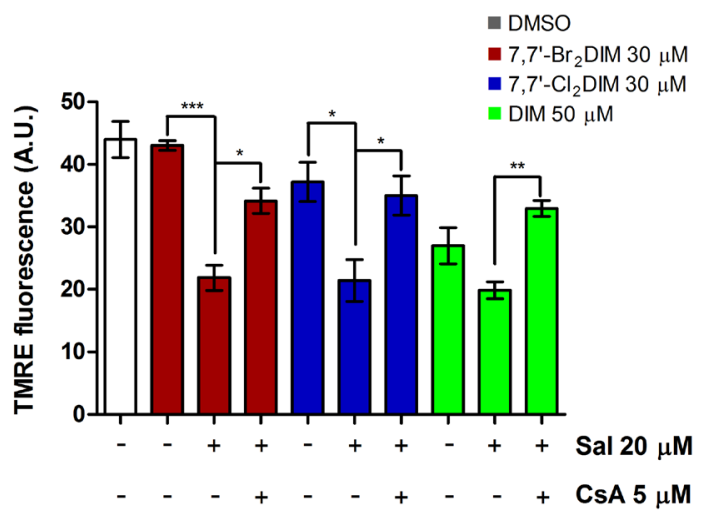

$\mathbf{E}$

$7,7^{\prime}-\mathrm{Cl}_{2} \mathrm{DIM}$

DIM

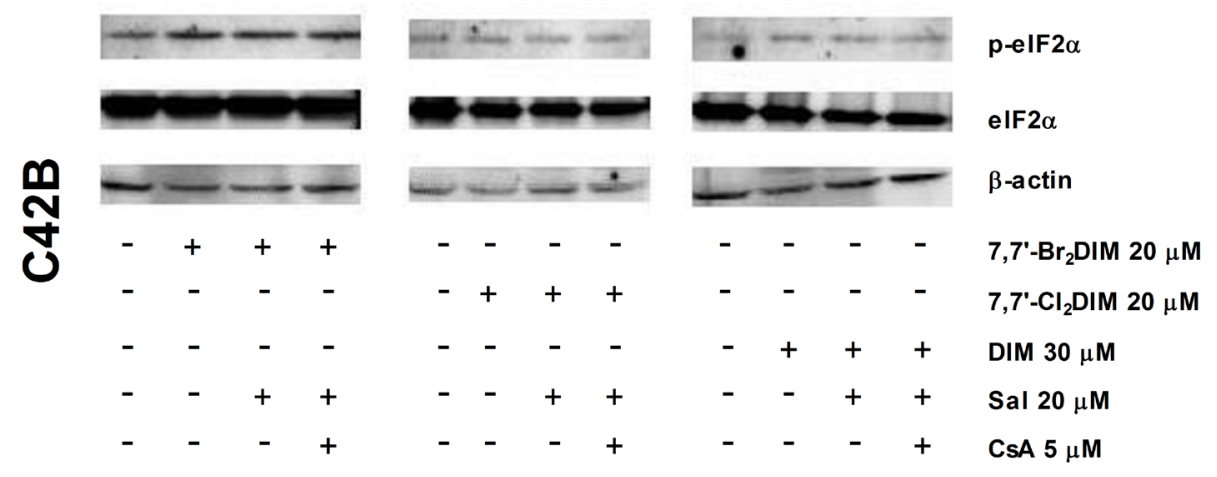

Figure 5: Cyclosporin A (CsA) abrogates salubrinal-mediated sensitization of prostate cancer cells to mitochondrial dysfunction using sub-toxic concentrations of 7,7'-dihaloDIMs or DIM. The percentage of intact LNCaP (A) and C42B (B) cells pre-treated for 4 hours with salubrinal, salubrinal and CsA, or $0.3 \%$ DMSO, followed by a 24 hour exposure to mildly toxic concentrations of 7,7'- $\mathrm{Br}_{2} \mathrm{DIM}, 7,7^{\prime}-\mathrm{Cl}_{2} \mathrm{DIM}$ or DIM. TMRE fluorescence of $\mathrm{LNCaP}(\mathbf{C})$ and $\mathrm{C} 42 \mathrm{~B}$ (D) cells pre-treated for 4 hours with salubrinal and cyclosporin A (CsA), or $0.3 \%$ DMSO followed by a 4 hour exposure to $7,7^{\prime}-\mathrm{Br}_{2} \mathrm{DIM}^{2}$ or $7,7^{\prime}-\mathrm{Cl}_{2} \mathrm{DIM}$. (E) Phosphorylation of eIF2 $\alpha$ in C42B cell extracts after a 24 hour exposure to mildly toxic concentrations of $7,7^{\prime}-\mathrm{Br}_{2} \mathrm{DIM}, 7,7^{\prime}-\mathrm{Cl}_{2} \mathrm{DIM}$ or DIM with or without a 4 hour pre-treatment with salubrinal, salubrinal and CsA, or $0.3 \%$ DMSO. 


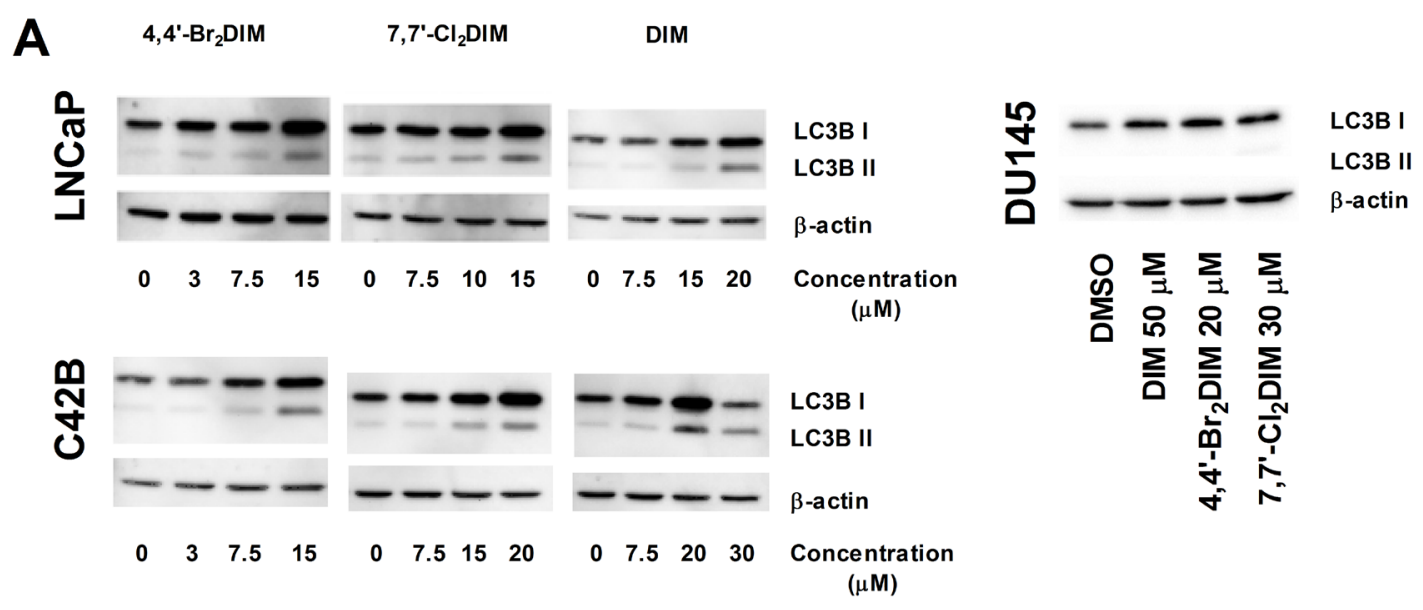

B

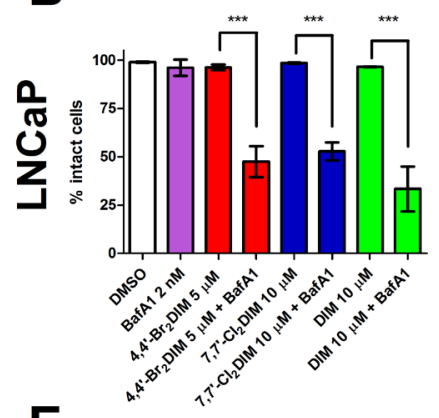

$\mathbf{E}$

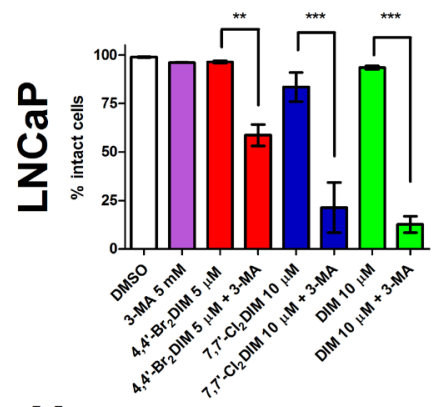

H

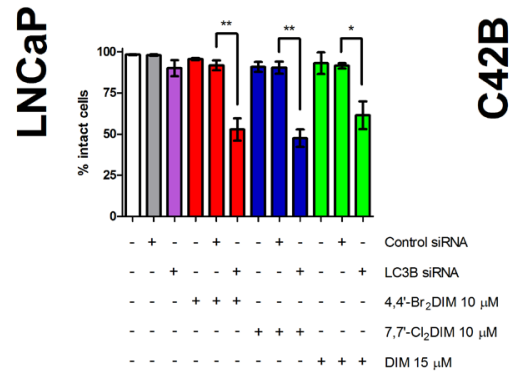

C

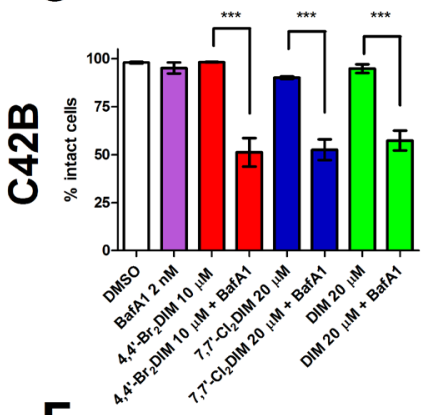

$\mathbf{F}$
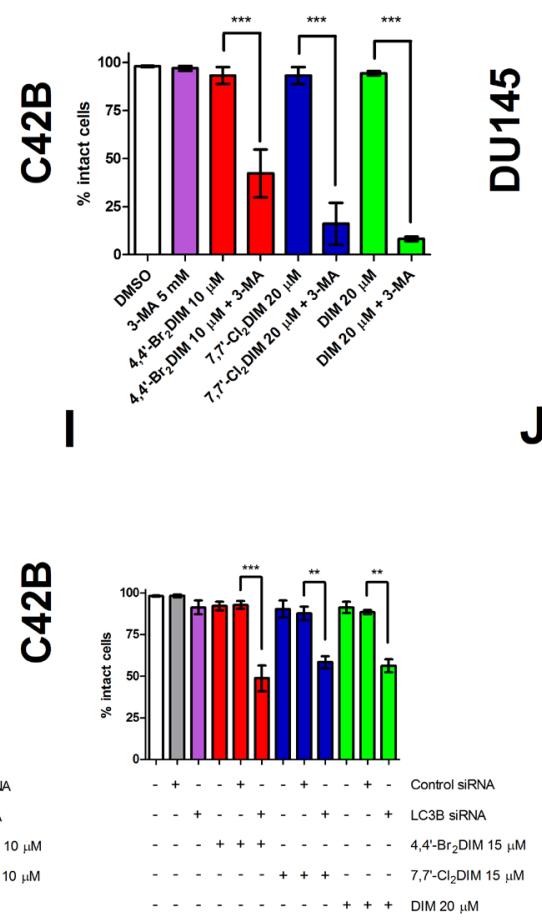
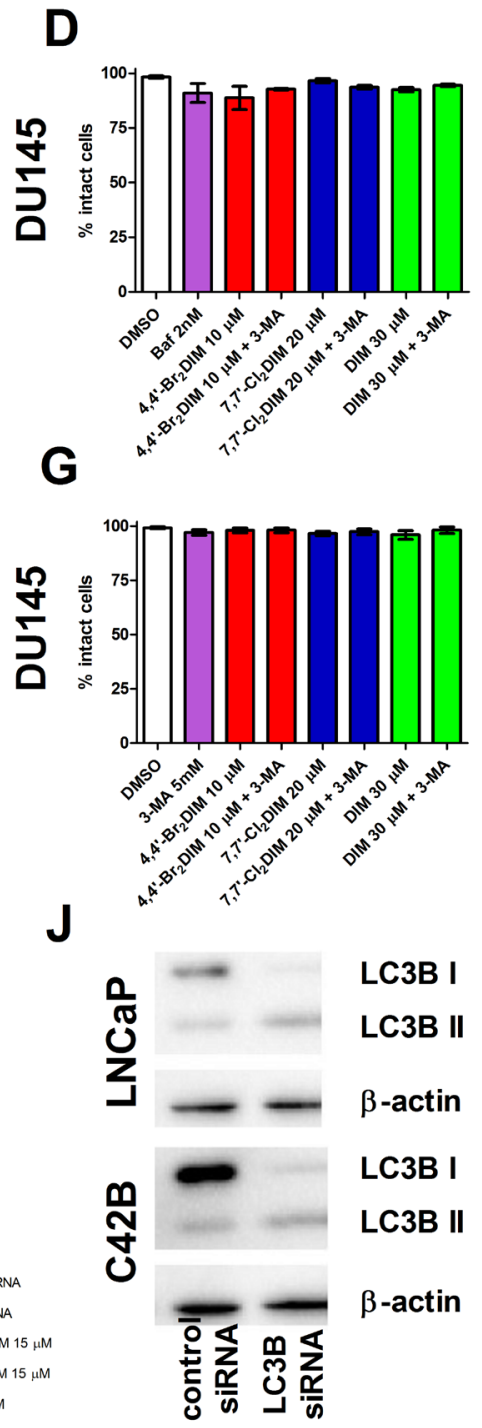

Figure 6: Ring-DIMs and DIM induce protective autophagy. (A) Levels of LC3B I and II protein in LNCaP, C42B and DU145 cells after a $24 \mathrm{hr}$ exposure to 4,4'-Br ${ }_{2}$ DIM, 7,7'-Cl DIM or DIM. Percentage of intact LNCaP (B, E),C42B (C, F) and DU145 (D, G) cells after a $24 \mathrm{~h}$ exposure to $4,4^{\prime}-\mathrm{Br}_{2} \mathrm{DIM}, 7,7^{\prime}-\mathrm{Cl}_{2} \mathrm{DIM}$ or DIM with or without a 4 hour pre-treatment with bafilomycin A1 (BafA1) or 3-methyladenine (3-MA). Percentage of intact $\mathrm{LNCaP}(\mathbf{H})$ and C42B (I) cells after a 24 hour exposure to 4,4'- $\mathrm{Br}_{2} \mathrm{DIM}, 7,7^{\prime}-\mathrm{Cl}_{2} \mathrm{DIM}$ or DIM with or without a 24 hour pre-treatment with LC3B siRNA. (J) Protein levels of LC3B I and II in LNCaP and C42B cells after treatment with or without LC3B siRNA. 

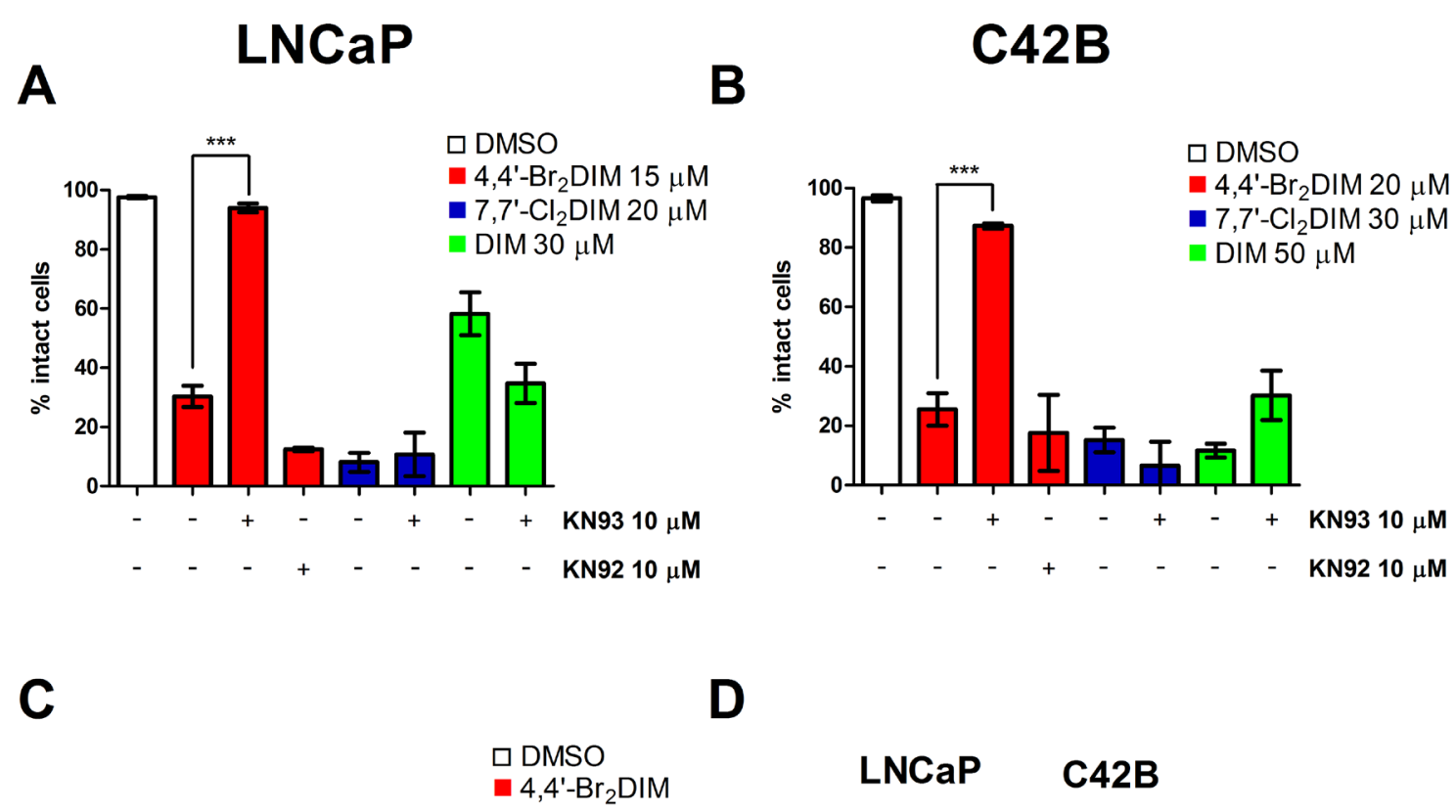

D
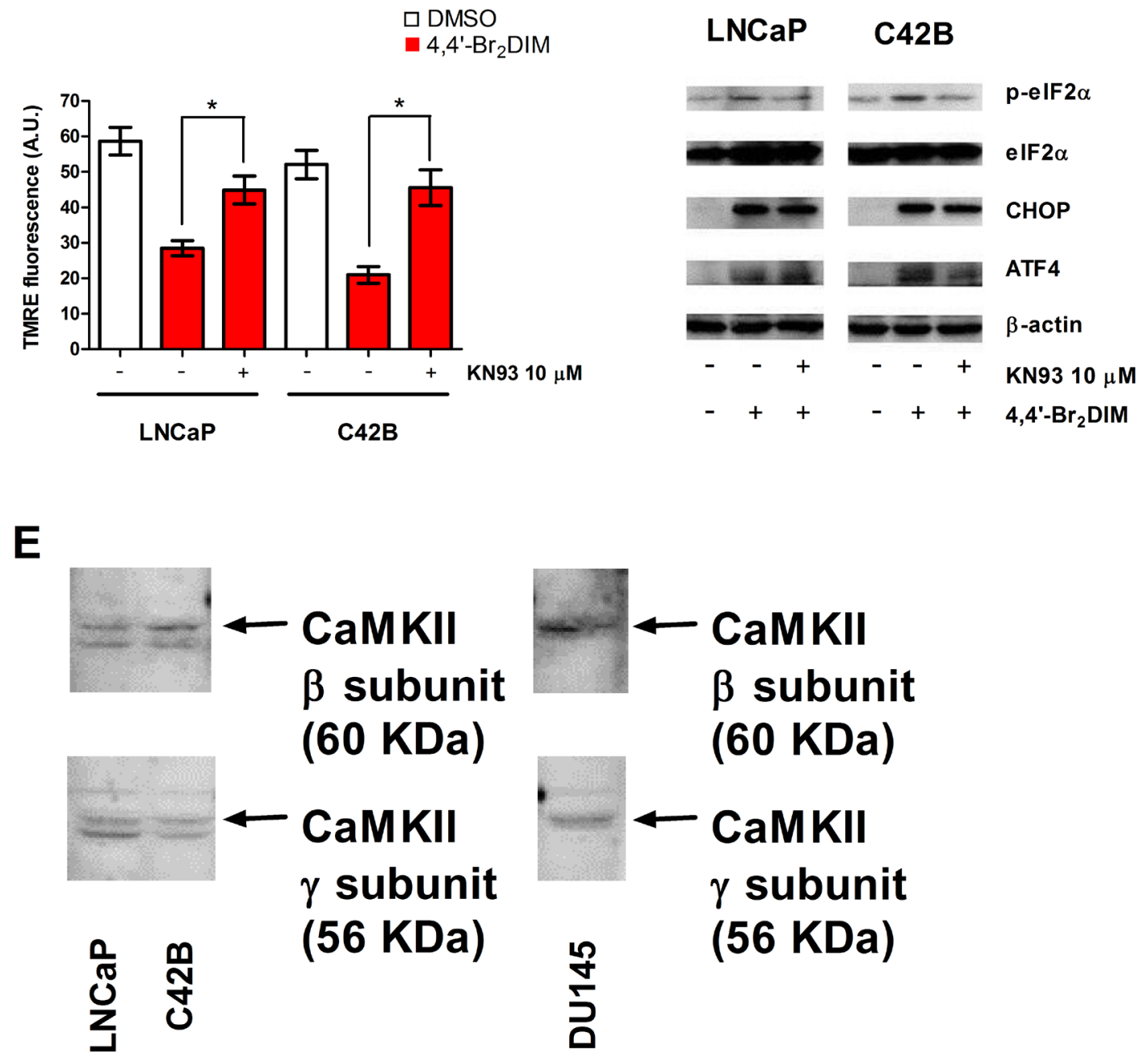

Figure 7: KN93 abrogates 4,4'-Br ${ }_{2} \mathrm{DIM}$ mediated cell death. Percentage of intact LNCaP (A) and C42B (B) cells after a 24 hour exposure to 4,4 '- $\mathrm{Br}_{2} \mathrm{DIM}, 7,7^{\prime}-\mathrm{Cl}_{2} \mathrm{DIM}$ or DIM with or without a 4 hour pre-treatment with KN92 or KN93. (C) TMRE fluorescence of LNCaP and C42B cells after a 4 hour exposure to 4,4'-Br ${ }_{2}$ DIM with or without a 4 hour pre-treatment with KN93. (D) Phosphorylation of eIF2 $\alpha$, and levels of ER stress proteins in $\mathrm{LNCaP}$ and C42B cells after a 24 hour exposure to 4,4'-Br${ }_{2} \mathrm{DIM}$ with or without a 4 hour pre-treatment with KN93. (E) Protein levels of $\mathrm{Ca}^{2+} /$ calmodulin-dependent protein kinase (CaMKII) beta and gamma subunits in $\mathrm{LNCaP}$, C42B and DU145 cells. 
dependent increase in LC3B conversion was observed in LNCaP and C42B cells, but not in autophagy-deficient DU145 cells, exposed to sub-toxic concentrations of 4,4'- $\mathrm{Br}_{2} \mathrm{DIM}$, 7,7'-Cl $\mathrm{DIM}$ or DIM for 24 hours (Fig. $6 \mathrm{~A})$. Pre-treatment of cells with autophagy inhibitors bafilomycin A1 (Fig. 6B-D) or 3-MA (Fig. 6E-G) sensitized LNCaP and C42B cells, but not DU145 cells, to sub-toxic concentrations of 4,4' $-\mathrm{Br}_{2} \mathrm{DIM}, 7,7^{\prime}-\mathrm{Cl}_{2} \mathrm{DIM}$ or DIM. We next silenced the LC3B gene in LNCaP and $\mathrm{C} 42 \mathrm{~B}$ cells using siRNA and then exposed them to sub-toxic concentrations of 4,4'- $\mathrm{Br}_{2} \mathrm{DIM}, 7,7^{\prime}-\mathrm{Cl}_{2} \mathrm{DIM}$ or DIM. We observed significant decreases in viability of cells treated with the LC3B-selective siRNA, but not control siRNA, with each of the three compounds (Fig. $6 \mathrm{H}, \mathrm{I})$. We confirmed the effectiveness of the LC3Bselective siRNA in decreasing the expression of LC3B in $\mathrm{LNCaP}$ and $\mathrm{C} 42 \mathrm{~B}$ cells to almost undetectable levels relative to control siRNA (Fig. 6J).

\section{In silico identification of protein targets for ring- DIMs and DIM}

To identify potential molecular targets for the ring-DIMs and DIM, we performed in silico 3-D affinity docking studies of 61 proteins with known 3-D crystal structures and which are involved in cell survival or death and mitochondrial function, to determine possible high-affinity interactions with the 4,4'-dihaloDIMs, 7,7'-dihaloDIMs and DIM. We identified CaMKII subunits alpha, beta and gamma, but not delta as possible high-affinity targets common to all five compounds (Table 1). Each compound had in silico docking affinities for each of the subunits with free energy values less than -8.5 $\mathrm{kcal} / \mathrm{mol}$, with a value lower than $-8.0 \mathrm{kcal} / \mathrm{mol}$ considered a high-affinity interaction.

\section{KN93 abrogates cell death induced by 4,4 '-Br ${ }_{2} \mathrm{DIM}$}

The involvement of the various CaMKII subunits in DIM or ring-DIM-mediated toxicity in prostate cancer cells was assessed using a selective CaMKII inhibitor, KN93. In LNCaP, C42B and DU145 cells, a 4 hour pre-treatment with KN93 resulted in a marked reduction of cell death caused by $4,4^{\prime}$ '- $\mathrm{Br}_{2} \mathrm{DIM}$, but not 7,7'-Cl ${ }_{2}$ DIM or DIM (Fig. 7A-B, Supplementary Fig. $\mathrm{S} 1 \mathrm{E})$. Additionally, KN92, an inactive derivative of KN93, did not abrogate cell death induced by 4,4'-Br 2 DIM (Fig. 7A-B, Supplementary Fig. S1E). Pre-treatment with KN93 restored the loss of MMP caused by 4,4'-Br ${ }_{2} \mathrm{DIM}$ in all three prostate cancer cell lines (Fig. 7C, Supplementary Fig. S1B). Pre-treatment of LNCaP and C42B cells with KN93 reduced 4,4'-Br ${ }_{2}$ DIM-mediated eIF2 $\alpha$ phosphorylation, but it did not affect $4,4^{\prime}-\mathrm{Br}_{2} \mathrm{DIM}-$ mediated increases in CHOP and ATF4 levels (Fig. 7D).
In DU-145 cells, pre-treatment with KN93 did not alter the increases in eIF2 $\alpha$ phosphorylation or levels of ATF4 and CHOP caused by 4,4'-Br ${ }_{2}$ DIM (Supplementary Fig. $\mathrm{S} 1 \mathrm{H})$. In addition, the expression of the beta and gamma subunits of CaMKII in LNCaP C42B, and DU145 cells was confirmed (Fig. 7E). The alpha and delta subunits of CaMKII were not found (data not shown).

\section{DISCUSSION}

\section{Ring-DIMs kill AD and AI prostate cancer cells but not non-tumourigenic RWPE-1 cells}

We have previously reported that ring-DIMs and DIM induce apoptosis and necrosis in androgen receptor-positive $(\mathrm{AR}+) \mathrm{AD} \mathrm{LNCaP}$ and in androgen receptor-negative (AR-) AI PC-3 prostate cancer cells. Similar to our previous report [17], 4,4'- $\mathrm{Br}_{2} \mathrm{DIM}$ induced cell death in AD AR+ LNCaP, AI AR+ C42B and AI AR- DU145 cells with the greatest potency of all five compounds tested. Concentrations of ring-DIMs that killed $100 \%$ of prostate cancer cells after 24 hours (20 $\mu \mathrm{M}$ for $4,4^{\prime}-\mathrm{Br}_{2} \mathrm{DIM}, 30 \mu \mathrm{M}$ for $7,7^{\prime}-\mathrm{Br}_{2} \mathrm{DIM}, 30 \mu \mathrm{M}$ for $7,7^{\prime}-\mathrm{Cl}_{2} \mathrm{DIM}, 50 \mu \mathrm{M}$ for $4,4^{\prime}-\mathrm{Cl}_{2} \mathrm{DIM}$ and $50 \mu \mathrm{M}$ for DIM) were not toxic to non-tumourigenic RWPE-1 prostate epithelial cells (Fig. 1). This confirms that DIM and its 4,4'- and 7,7' - ring-substituted analogs selectively affect processes and pathways that are dysregulated in cancerous tissues, and are not toxic to normal cells.

\section{Cell death induced by the ring-DIMs is dependent on mitochondrial dysfunction but not ER stress or autophagy}

In our previous study, we hypothesized that $4,4^{\prime}-\mathrm{Br}_{2} \mathrm{DIM}$ induces cell death by independently activating both intrinsic and extrinsic apoptosis pathways based on the observation that this derivative activated caspases- 8 and -9 , but did not increase Bid cleavage. We further hypothesized that ER stress plays a role in ring-DIM-induced cell death, as both $4,4^{\prime}-\mathrm{Br}_{2} \mathrm{DIM}$ and $7,7^{\prime}-\mathrm{Cl}_{2} \mathrm{DIM}$ induced increased expression of DR4 and DR5, and 4,4'-Br ${ }_{2}$ DIM also increased Fas receptor and Fas ligand (FasL) [17]. Here, we show that ER stress and mitochondrial dysfunction are early events in ringDIM- and DIM-induced prostate cancer cell death. ATF4 expression was increased by 4,4'-Br ${ }_{2}$ DIM within 1 hour of exposure, while $7,7^{\prime}-\mathrm{Cl}_{2} \mathrm{DIM}$ and DIM increased ATF4 expression after 4 hours. We observed a significant decrease in MMP in cells treated with 4,4'-dihaloDIMs and DIM, but only a slight decrease in mitochondrial activity of cells treated with 7,7'-dihaloDIMs (Fig. 2). CsA, a potent inhibitor of the mitochondrial permeability transition pore (mPTP) complex, completely abrogated 
ring-DIM-induced death of $\mathrm{LNCaP}$ and $\mathrm{C} 42 \mathrm{~B}$ cells, but could not prevent DIM-induced cell death (Fig. 3). CsA also abrogated the toxicity of $4,4^{\prime}-\mathrm{Br}_{2} \mathrm{DIM}$ in DU-145 cells (Supplementary Figure S1B, E). The loss of MMP was inhibited by $\mathrm{CsA}$ in cells treated with the ring-DIMs as well as DIM, suggesting that mitochondrial dysfunction is necessary for cell death caused by the ring-DIMs but not DIM. However, pre-treatment with CsA did not abrogate eIF2 $\alpha$ phosphorylation or cause a decline in the levels of ATF4 or CHOP in cells treated with either $4,4{ }^{\prime}-\mathrm{Br}_{2} \mathrm{DIM}$, $7,7^{\prime}-\mathrm{Cl}_{2}$ DIM or DIM (Fig. 3E-G). Therefore, our results suggest that ring-DIM-mediated ER stress is activated in parallel, and not downstream, of mitochondrial dysfunction. It has been reported previously that eIF $2 \alpha$ could play a role in the survival of tumourigenic cells in response to Akt inhibition [39], and DIM has been shown to be a potent inhibitor of the Akt pathway [15, 40]. Our in silico data support the notion that DIM may act as a direct Akt inhibitor, as Akt showed a significant binding affinity to DIM and the ring-DIMs (Supplementary Table S1). Therefore, the observed induction of ER stress may be a pro-survival response to the mitochondrial disruption caused by the ring-DIMs and DIM, and is not necessary for ring-DIM-induced toxicity.
Although ER stress does not appear to be responsible for ring-DIM-induce cell death, we wished to confirm this using salubrinal, a compound commonly used to inhibit ER stress by blocking dephosphorylation of eIF $2 \alpha$. Pre-treatment with $20 \mu \mathrm{M}$ of salubrinal inhibited cell death caused by 4,4 ' $-\mathrm{Br}_{2} \mathrm{DIM}$ and 4,4 ' $-\mathrm{Cl}_{2} \mathrm{DIM}$ in LNCaP and C42B cells, and by 4,4'-Br DIM in DU145 cells. In contrast, pre-treatment with salubrinal sensitized LNCaP and C42B cells to the toxicity of $7,7^{\prime}-\mathrm{Br}_{2} \mathrm{DIM}$, 7,7'-Cl ${ }_{2}$ DIM and DIM (Fig. 4A, B). Interestingly, the increased phosphorylation of eIF $2 \alpha$ mediated by $4,4^{\prime}$ - $\mathrm{Br}_{2}$ DIM was abrogated by pre-treatment with salubrinal in all three cell lines (Fig. 4E; Supplementary Fig S1G). However, in LNCaP and C42B cells, pretreatment with salubrinal did not consistently abrogate the 4,4'-Br ${ }_{2}$ DIM-induced levels of CHOP or ATF4 (Fig. $4 \mathrm{E}$ ), and in DU145 cells salubrinal only partially reduced the 4,4'-Br ${ }_{2}$ DIM-induced expression of these markers of ER stress (Supplementary Fig S1G). Moreover, salubrinal alone did not affect phosphorylation of eIF $2 \alpha$ in all three cell lines (Fig. S2A, B), suggesting that, in prostate cancer cells, salubrinal does not directly modify the phosphorylation status of eIF $2 \alpha$; nor does it significantly inhibit the onset of ring-DIM-mediated ER stress. These

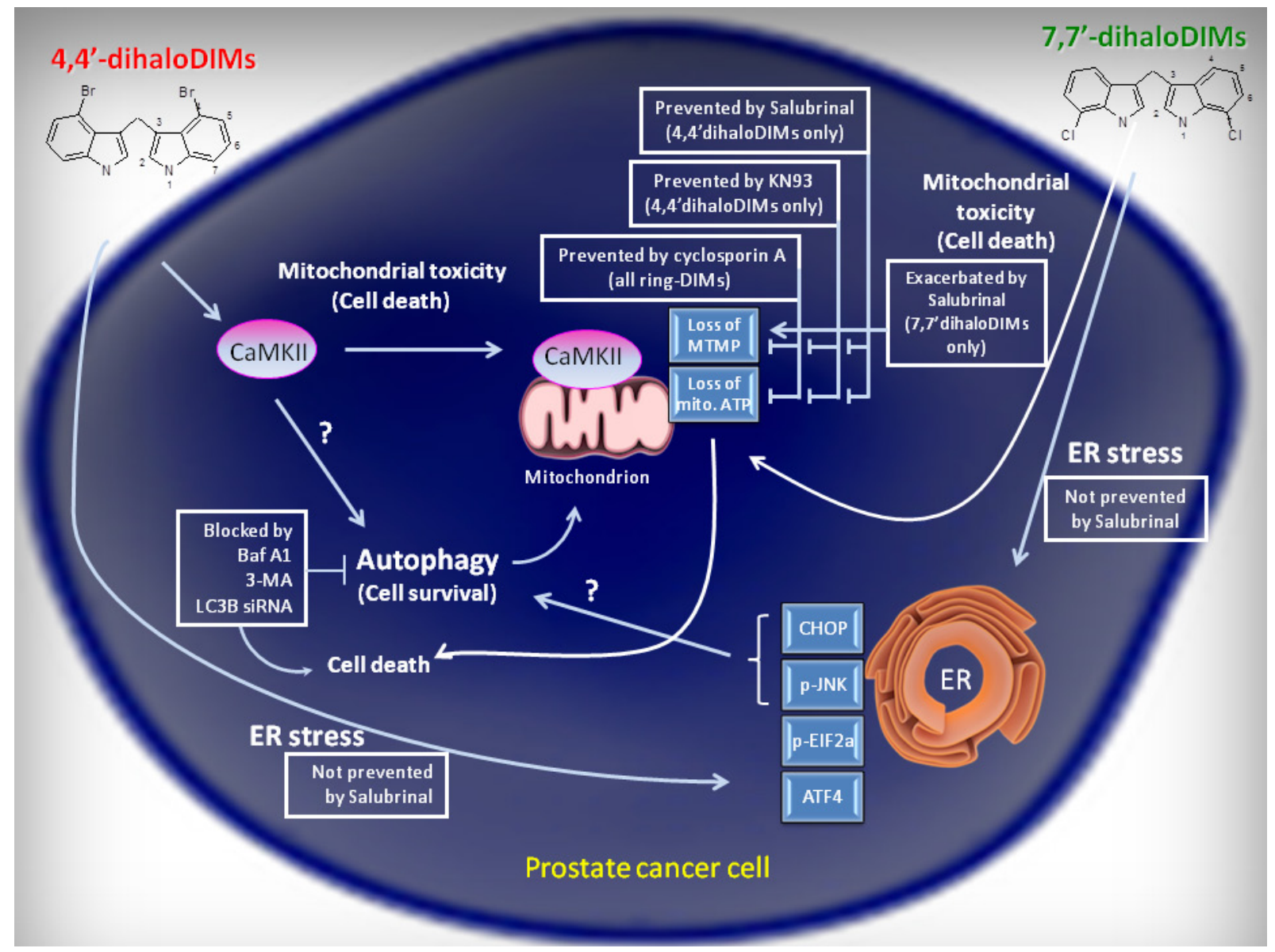

Figure 8: A schematic representation of the differential pathways activated by the 4,4'- and 7,7'-dihalogenated ringDIMs and their role in ring-DIM-induced prostate cancer cell death. 
results are consistent with two other reports showing that salubrinal did not modify the phosphorylation status of eIF $2 \alpha$, and interacted directly with Bcl-2 [41, 42]. We propose that the mitochondrion is a novel target of salubrinal which differentially modulates the disruption of mitochondrial stability caused by the ring-DIMs: whereas salubrinal abrogates 4,4'- $\mathrm{Br}_{2}$ DIM-mediated loss of MMP (Fig. 4C, D), it exacerbates the loss of MMP induced by 7,7'-dihaloDIMs and DIM (Fig. 5C, D). Furthermore, it appears that salubrinal's ability to modulate the cell death caused by the ring-DIMs is dependent on the loss of MMP, as pre-treatment with CsA negated the synergistic cytotoxic effects of co-treatment with salubrinal and 7,7'-dihaloDIMs or DIM (Fig. 5A-D). Future studies will investigate the mitochondrial target(s) affected by salubrinal, and how they may be utilized to further increase the cytotoxic potency of the 7,7'-dihaloDIMs and DIM in prostate cancer cells.

DIM has been shown to induce ER stress-dependent autophagy in ovarian cancer cells, with the autophagic response being partially responsible for DIM-mediated cell death in vitro and in vivo [27]. In contrast, our studies show that DIM- and ring-DIM-mediated autophagy is cytoprotective, since pre-treatment with either bafilomycin A1, 3-MA or transcriptional silencing of LC3B sensitized both LNCaP and C42B cells to cell death induced by DIM or the ring-DIMs. However, in DU145 cells, which are autophagy-deficient due to a mutation in the $A T G 5$ gene leading to the premature termination of ATG5 transcripts [43], bafilomycin A1 and 3-MA had no effect (Fig. 6). Additionally, Kandala and Srivastava [27] provided evidence that DIM mediated autophagy was dependent on CHOP signalling. However, in LNCaP, C42B and DU145 cells, ER stress was not sufficient to induce cell death in prostate cancer cells. Thus, it is possible that the onset of ER stress might also serve a cytoprotective function in prostate cancer cells by activating autophagy via $\mathrm{CHOP}$ signaling.

\section{Is $\mathrm{Ca}^{2+}$ /calmodulin-dependent protein kinase (CaMKII) involved in 4,4'-Br ${ }_{2}$ DIM-mediated mitochondrial dysfunction?}

Our in silico docking experiments revealed CaMKII as a potential high affinity target for the ring-DIMs and DIM (Table 1). In prostate cancer cells, CaMKII activity has been implicated in cell survival and loss of androgendependence [44]. However, in a variety of cases, CaMKII can be pro-apoptotic and in hepatocellular carcinoma cells CaMKII is necessary for melittin-induced apoptosis [13], and CaMKII activation has been linked to sustained c-Jun N-terminal kinase and p38 mitogen-activated kinase stress signaling [13, 45, 46]. Moreover, CaMKII has been shown to play a role in the simultaneous induction of ER stress and mitochondrial dysfunction [46]. We observed that KN93, a selective inhibitor of CaMKII, but not its inactive form KN92, prevented the death of cells treated with $4,4^{\prime}-\mathrm{Br}_{2} \mathrm{DIM}$, but not $7,7^{\prime}-\mathrm{Cl}_{2} \mathrm{DIM}$ or DIM (Fig. 7A, B). In addition, KN93 abrogated the loss of MMP observed after exposure to $4,4^{\prime}-\mathrm{Br}_{2} \mathrm{DIM}$ and decreased eIF2 $\alpha$ phosphorylation, but did not significantly prevent expression of ATF4 or CHOP (Fig. 7D). Thus, CaMKII activation may directly initiate the intrinsic pathway of apoptosis in prostate cancer cells, and this effect is independent of induction of ER stress. Interestingly, we found protein expression of only the beta and gamma subunits of CaMKII in the three prostate cancer cell lines tested (Fig. 7E), with both subunits exhibiting high docking affinity values for $4,4^{\prime}-\mathrm{Br}_{2} \mathrm{DIM}$ (Table 1 ). The crystal structure of CaMKII-beta and the docking site of each ring-DIM and DIM are shown in Supplementary Fig. S3. C42B cells have been shown to transcriptionally express all four subunits of CaMKII (alpha, beta, gamma, delta), whereas LNCaP and DU145 cells only expressed the beta, gamma and delta transcripts [47]. Our study confirms that the CaMKII-beta and -gamma proteins are indeed produced from these transcripts, but that protein levels of the CaMKII-alpha and -delta subunits are undetectable in each of the three cell lines. These data suggest that CaMKII may be a selective upstream target of $4,4^{\prime}-\mathrm{Br}_{2} \mathrm{DIM}$ that is responsible for the early onset of mitochondrial dysfunction and ER stress in prostate cancer cells. Although our in silico analysis identified a potential interaction between CaMKII and 7,7'- $\mathrm{Cl}_{2} \mathrm{DIM}$ and between CaMKII and DIM, it appears that CaMKII activity is not necessary for $7,7^{\prime}-\mathrm{Cl}_{2} \mathrm{DIM}$ - or DIMmediated cell death. This differential response between the 4,4'-dihalo- and 7,7'-dihaloDIMs to inhibition of CaMKII by KN93 provides further evidence that the mechanisms of action of the ring-DIMs is highly structure-dependent. We previously showed that the 4,4'-dihaloDIMs, but not the 7,7'-dihaloDIMs induced the Fas receptor and FasL in LNCaP cells [17]; additionally, the 7,7'-dihaloDIMs were shown to be more potent inhibitors of DHTmediated LNCaP cell proliferation than the 4,4'-dihaloDIMs [17]. In the present study we also show that the 4,4'- and 7,7'-dihaloDIMs elicit opposite responses in prostate cancer cells pre-treated with salubrinal, but that these effects are unrelated to ER stress. Moreover, pretreatment of all three cell lines with KN93 did not prevent the increase in expression of either CHOP or ATF4, further confirming that ER stress is not a key contributor to 4,4 '- $-\mathrm{Br}_{2} \mathrm{DIM}$-mediated cell death.

\section{CONCLUSION}

We have confirmed that ring-substituted dihaloDIMs act via distinct, structure-dependent, yet overlapping mechanisms (Figure 8) to induce potent cytotoxic effects in $\mathrm{AD}$ and $\mathrm{AI}$ prostate cancer cells, but not normal prostate epithelium. We have shown that cell death mediated by 
the most potent ring-DIM, 4,4'- $\mathrm{Br}_{2} \mathrm{DIM}$, is dependent on CaMKII activation and subsequent mitochondrial dysfunction, and that ER stress is insufficient to induce cell death in response to either the ring-DIMs or DIM. We also show that the ring-DIMs and DIM induce protective autophagy in prostate cancer cells. Future studies will concentrate on the relationship between 4,4 ' $-\mathrm{Br}_{2} \mathrm{DIM}$, CaMKII and mitochondrial dysfunction, the effectiveness of this potent anti-cancer compound in animal models of prostate cancer, and the potential for targeting the ER stress and autophagy pathways in order to increase the effectiveness of the ring-DIMs and DIM as anti-neoplastic agents.

\section{MATERIALS AND METHODS}

\section{Cell lines and reagents}

LNCaP, and DU145 human prostate cancer cells as well as RWPE-1 immortalized normal prostate epithelial cells were purchased from the American Type Culture Collection (Manassas, VA). LNCaP C4-2B (C42B) cells were purchased from the $\mathrm{MD}$ Anderson Cancer Center (Houston, TX). LNCaP, C42B, DU145, and RWPE-1 cells were grown in RPMI 1640 supplemented with 10\% fetal bovine serum, $2 \mathrm{mM}$ L-glutamine, 1\% HEPES, $1 \%$ sodium-pyruvate and $10 \mathrm{ml} / \mathrm{L}$ of $100 \mathrm{x}$ antibioticantimycotic solution (Sigma-Aldrich, St-Louis, MO). Cells were maintained in a humidified atmosphere $(5 \%$ $\mathrm{CO}_{2}$ ) at $37^{\circ} \mathrm{C}$. Ring-substituted 4,4'- and 7,7'-dihaloDIMs were synthesized in our laboratories at $>95 \%$ purity and were dissolved in $100 \%$ dimethyl sulfoxide (DMSO) to obtain $100 \mathrm{mM}$ stock solutions. Dihydrotestosterone (DHT; Steraloids Inc., Newport, RI) was dissolved in DMSO to make a $100 \mathrm{mM}$ stock solution. Cyclosporin A (CsA; Cell Signaling, Beverly, MA), salubrinal (Enzo Life Sciences, Farmingdale, NY), KN92, KN93 (Millipore, Billerica, MA) and bafilomycin A1 (Sigma Aldrich) were dissolved in DMSO as 1000-fold concentrated stock solutions. The final concentration of DMSO in culture medium was $0.1 \%$ for single exposures and not greater than $0.3 \%$ for combined exposures.

\section{Treatment of cells with ring-DIMs, pharmacological inhibitors and siRNA}

LNCaP, C42B, and DU145 cells were exposed to the ring-DIMs at the indicated final concentrations in their respective culture medium, supplemented with $2 \%$ dextran-coated charcoal-stripped FBS. DHT was added to LNCaP cells after serial dilution in DMSO to a working stock solution of $100 \mathrm{nM}$, resulting in a final DHT concentration of $0.1 \mathrm{nM}$ in culture medium. CsA, KN92 and KN93, salubrinal, bafilomycin A1 were added to cell cultures 4 hours prior to treatment with either ringDIMs, DIM or DMSO vehicle control. 3-Methyladenine was dissolved directly in water and added freshly to the cells 4 hours prior to exposure to the diindolylmethane compounds.

For siRNA experiments, LNCaP or C42B cells were transfected with SMARTpool ON-TARGETplus siRNA oligonucleotide for $L C 3 B$ (Dharmacon, USA) using lipofectamine RNAiMAX (Life Technologies, USA) in serum free Opti-MEM according to manufacturer's protocols. ON-TARGETplus Non-targeting Control siRNAs was used a negative control. After a 24-hour incubation, transfected cells were exposed to the ring DIMs, DIM or vehicle control for a further 24 hours.

\section{Cell death and mitochondrial membrane potential (MMP)}

For cell death measurements, LNCaP, C42B, and DU145 cells were seeded in 24-well plates in 2\% stripped FBS. Cells were then treated with (LNCaP) or without (C42B, DU145) 0.1 nM DHT and several concentrations of ring-DIMs, DIM or vehicle control (DMSO). After 24 hours, Hoechst 33342 (Sigma-Aldrich) and propidium iodide (PI; Invitrogen, Carlsbad, CA) stains were both added to each well at a concentration of $1 \mu \mathrm{g} / \mathrm{ml}$ (in water) after which the plates were incubated for 15 minutes at $37^{\circ} \mathrm{C}$. Hoechst- and PI-positive cells were then counted under a Nikon Eclipse (TE-2000U) inverted fluorescence microscope at 20x magnification using filter cubes with excitation wavelengths of 330-380 and 532-587 nm, respectively. Intact cells were counted as exhibiting neither chromatin condensation, chromatin fragmentation nor PI staining. To measure MMP, tetramethylrhodamine ethyl ester (TMRE) was added to each well at a final concentration of $50 \mathrm{nM}$ for 15 minutes at $37^{\circ} \mathrm{C}$. TMRE is a cell permeable, positively charged dye that accumulates in active negatively charged mitochondria. In inactive or (partially) depolarized mitochondria, membranes have decreased potential and fail to sequester TMRE. Cells were then observed under an inverted fluorescence microscope using a filter cube with an excitation wavelength of 532$587 \mathrm{~nm}$. The photos of cells treated with either TMRE, Hoechst 33342 or PI were analyzed using ImageJ image processing software [29].

\section{ATP measurements}

LNCaP, C42B, and DU145 cells were seeded in 96-well plates in 2\% stripped-FBS. Cells were then treated with (LNCaP) or without (C42B, DU145) 0.1 nM DHT and several concentrations of ring-DIMs, DIM or DMSO alone. A $0.5 \mathrm{M}$ stock solution of 2-deoxy-Dglucose (Sigma-Aldrich) was prepared in water and added to the wells at a final concentration of $5 \mathrm{mM} 4$ hours 
prior to addition of ring-DIMs, DIM or DMSO alone. Mitochondrial ATP levels were measured 1 hour later using a ViaLight Plus kit (Lonza, Basel, Switzerland). Briefly, cells were treated for 10 minutes with lysis buffer, after which a bioluminescent ATP monitoring reagent was added to each well for 2 minutes. The bioluminescent signal was measured using a SpectroMax M5 microplate reader (Molecular Devices, Sunnydale, CA).

\section{SDS-PAGE and immunoblotting}

Crude protein extracts $(50 \mu \mathrm{g})$ were resolved by electrophoresis in $10 \%$ sodium dodecyl sulfatepolyacrylamide gels and then transferred to PVDF Immobilon-P membranes (Bio-Rad, Mississauga, ON). Blots were blocked using 5\% milk powder (Selection brand, Marché Jean-Talon, Montréal, QC) and incubated with antibodies using a dilution of 1:500 for anti- $\beta$-actin, a 1:250 dilution for anti-CaMKII beta subunit and antiCaMKII gamma subunit (Santa Cruz Biotechnology, Santa Cruz, CA), a 1:500 dilution for anti-CHOP, a 1:1000 dilution for anti-LC3B, anti-ATF4, anti-phospho eIF2 $\alpha$ (Ser51), and a 1:10000 dilution for anti-eIF2 $\alpha$ (Cell Signaling). Immunoreactive proteins were exposed to antirabbit or anti-mouse horseradish peroxidise-conjugated secondary antibodies (Millipore) that were diluted 1:5000. Antigen-antibody complexes were detected using Immobilon ECL Western Chemiluminescent HRP Substrate (Millipore) and recorded with a VersaDoc imaging system (Bio-Rad).

\section{In Silico 3-D affinity docking analyses}

The structures of DIM and the ring-DIMs were optimized in a Gaussian 09 program package (Frisch et al., 2004) by the Density Functional Theory (DFT) method at the B3LYP/6-31G level. The output file was translated to $\mathrm{pdb}$ and pdbqt formats using Open Babel [30] and AutoDock Tools [31], respectively. The 3-D structures of the proteins were downloaded from the Protein Data Bank (PDB) in pdb format [32]. The structure of TrailR1 was obtained from ModBase because its crystal structure was not reported in PDB. Protein structures were then prepared using Sybyl-X 2.0 (Tripos, St. Louis, MO). In this process, all ions, water molecules and other substructures were removed [33]. We also fixed all side-chains, backbones and protonation types. Once prepared, proteins underwent a two-step optimization procedure using Sybyl-X 2.0. The first step included the Powell method applying Kollman"s united force field AMBER (Assisted Model Building with Energy Refinement) charges, dielectric constant 1.0, NB cutoff 8.0, maximum interactions 1000 and termination gradient $0.001 \mathrm{kcal} / \mathrm{mol}$. The second step utilized Kollman's All Atom approach with the same parameters. The resultant structures were saved as pdb files and then converted to pdbqt format using AutoDock Tools [31]. Kollman charges and polar hydrogen atoms were added to the 3-D structures of the proteins using the same software [34].

Docking and docking-refinement experiments were carried out through a blind docking strategy by AutoDock Vina [35] to allow inclusion of the whole protein surface and all possible binding sites. The 3-D docking grid was centered on the macromolecule [36] and coordinates were calculated with a resolution of $0.357 \AA$ using AutoDock Tools [31]. Docking analyses were performed with the AutoDock Vina 1.1 molecular docking and virtual screening program [35] running on a Linux operating system using the following settings: energy range $=1.5$, number of modes $=20$ and exhaustiveness $=25$. The docking models of protein/DIM and protein/ring-DIM complexes with high-affinity scores (less than $-8.0 \mathrm{kcal} /$ $\mathrm{mol}$ ) were refined with repetitions of 100 runs to increase accuracy and identify alternative in silico binding sites for each compound.

Protein/compound complexes underwent conformational analyses to determine the contact residues and interaction type using LigandScout 3.1 software with default settings [37]. The interaction cutoff threshold of the pdb interpretation, which defines a sphere around the ligand, was set at $7.0 \AA$. The atoms of the protein found inside the ligand-sphere were considered to be able to interact with the ligand [38].

\section{Statistical analyses}

All experiments were performed in at least triplicate and results presented as mean \pm SEM. Statistically significant differences $(* \mathrm{P}<0.05, * * \mathrm{P}<0.01, * * * \mathrm{P}<$ $0.005)$ were calculated using a two-tailed Student t-test. $\mathrm{IC}_{50}$ values were calculated using nonlinear curve-fit analysis. All analyses were performed using GraphPad Prism v5.03 (GraphPad Software, San Diego, CA).

\section{REFERENCES}

1. Siegel R, Naishadham D and Jemal A. Cancer statistics, 2013. CA Cancer J Clin. 2013; 63:11-30.

2. McLeod DG. Tolerability of Nonsteroidal Antiandrogens in the Treatment of Advanced Prostate Cancer. Oncologist. 1997; 2:18-27.

3. Wysowski DK, Freiman JP, Tourtelot JB and Horton ML, 3rd. Fatal and nonfatal hepatotoxicity associated with flutamide. Ann Intern Med. 1993; 118:860-864.

4. Bjeldanes LF, Kim JY, Grose KR, Bartholomew JC and Bradfield CA. Aromatic hydrocarbon responsivenessreceptor agonists generated from indole-3-carbinol in vitro and in vivo: comparisons with 2,3,7,8-tetrachlorodibenzop-dioxin. Proc Natl Acad Sci U S A. 1991; 88:9543-9547.

5. De Kruif CA, Marsman JW, Venekamp JC, Falke HE, 
Noordhoek J, Blaauboer BJ and Wortelboer HM. Structure elucidation of acid reaction products of indole-3-carbinol: detection in vivo and enzyme induction in vitro. Chem Biol Interact. 1991; 80:303-315.

6. Ge X, Yannai S, Rennert G, Gruener N and Fares FA. 3,3'-Diindolylmethane induces apoptosis in human cancer cells. Biochem Biophys Res Commun. 1996; 228:153-158.

7. Nachshon-Kedmi M, Fares FA and Yannai S. Therapeutic activity of 3,3'-diindolylmethane on prostate cancer in an in vivo model. Prostate. 2004; 61:153-160.

8. Heath EI, Heilbrun LK, Li J, Vaishampayan U, Harper F, Pemberton P and Sarkar FH. A phase I dose-escalation study of oral BR-DIM (BioResponse 3,3'- Diindolylmethane) in castrate-resistant, non-metastatic prostate cancer. Am J Transl Res. 2010; 2:402-411.

9. Bhuiyan MM, Li Y, Banerjee S, Ahmed F, Wang Z, Ali $\mathrm{S}$ and Sarkar FH. Down-regulation of androgen receptor by 3,3'-diindolylmethane contributes to inhibition of cell proliferation and induction of apoptosis in both hormonesensitive LNCaP and insensitive C4-2B prostate cancer cells. Cancer Res. 2006; 66:10064-10072.

10. Le HT, Schaldach CM, Firestone GL and Bjeldanes LF. Plant-derived 3,3'-diindolylmethane is a strong androgen antagonist in human prostate cancer cells. J Biol Chem. 2003; 278:21136-21145

11. Abdelbaqi K, Lack N, Guns ET, Kotha L, Safe S and Sanderson JT. Antiandrogenic and growth inhibitory effects of ring-substituted analogs of 3,3'-diindolylmethane (RingDIMs) in hormone-responsive LNCaP human prostate cancer cells. Prostate. 2011; 71:1401-1412.

12. Wang TT, Schoene NW, Milner JA and Kim YS. Broccoli-derived phytochemicals indole-3-carbinol and 3,3'-diindolylmethane exerts concentration-dependent pleiotropic effects on prostate cancer cells: comparison with other cancer preventive phytochemicals. Mol Carcinog. 2012; 51:244-256.

13. Chinnakannu K, Chen D, Li Y, Wang Z, Dou QP, Reddy GP and Sarkar FH. Cell cycle-dependent effects of 3,3'-diindolylmethane on proliferation and apoptosis of prostate cancer cells. J Cell Physiol. 2009; 219:94-99.

14. Gao N, Cheng S, Budhraja A, Liu EH, Chen J, Chen D, Yang Z, Luo J, Shi X and Zhang Z. 3,3'-Diindolylmethane exhibits antileukemic activity in vitro and in vivo through a Akt-dependent process. PLoS One. 2012; 7:e31783.

15. Garikapaty VP, Ashok BT, Tadi K, Mittelman A and Tiwari RK. 3,3'-Diindolylmethane downregulates pro-survival pathway in hormone independent prostate cancer. Biochem Biophys Res Commun. 2006; 340:718-725.

16. Kong D, Banerjee S, Huang W, Li Y, Wang Z, Kim HR and Sarkar FH. Mammalian target of rapamycin repression by 3,3'-diindolylmethane inhibits invasion and angiogenesis in platelet-derived growth factor-D-overexpressing PC3 cells. Cancer Res. 2008; 68:1927-1934.

17. Goldberg AA, Titorenko VI, Beach A, Abdelbaqi K,
Safe S and Sanderson JT. Ring-substituted analogs of 3,3'-diindolylmethane (DIM) induce apoptosis and necrosis in androgen-dependent and -independent prostate cancer cells. Invest New Drugs. 2013.

18. Li Y, Wang Z, Kong D, Murthy S, Dou QP, Sheng S, Reddy GP and Sarkar FH. Regulation of FOXO3a/beta-catenin/ GSK-3beta signaling by 3,3'-diindolylmethane contributes to inhibition of cell proliferation and induction of apoptosis in prostate cancer cells. J Biol Chem. 2007; 282:2154221550 .

19. Li XJ, Park ES, Park MH and Kim SM. 3,3'-Diindolylmethane suppresses the growth of gastric cancer cells via activation of the Hippo signaling pathway. Oncol Rep. 2013; 30:2419-2426.

20. Nachshon-Kedmi M, Yannai S, Haj A and Fares FA. Indole3-carbinol and 3,3'-diindolylmethane induce apoptosis in human prostate cancer cells. Food Chem Toxicol. 2003; 41:745-752.

21. Abdelrahim M, Newman K, Vanderlaag K, Samudio I and Safe S. 3,3'-diindolylmethane (DIM) and its derivatives induce apoptosis in pancreatic cancer cells through endoplasmic reticulum stress-dependent upregulation of DR5. Carcinogenesis. 2006; 27:717-728.

22. Savino JA, 3rd, Evans JF, Rabinowitz D, Auborn KJ and Carter TH. Multiple, disparate roles for calcium signaling in apoptosis of human prostate and cervical cancer cells exposed to diindolylmethane. Mol Cancer Ther. 2006; 5:556-563.

23. Sun S, Han J, Ralph WM, Jr., Chandrasekaran A, Liu K, Auborn KJ and Carter TH. Endoplasmic reticulum stress as a correlate of cytotoxicity in human tumor cells exposed to diindolylmethane in vitro. Cell Stress Chaperones. 2004; 9:76-87.

24. Gong Y, Sohn H, Xue L, Firestone GL and Bjeldanes LF. 3,3'-Diindolylmethane is a novel mitochondrial $\mathrm{H}(+)$ ATP synthase inhibitor that can induce p21(Cip1/Waf1) expression by induction of oxidative stress in human breast cancer cells. Cancer Res. 2006; 66:4880-4887.

25. Riby JE, Firestone GL and Bjeldanes LF. 3,3'-diindolylmethane reduces levels of HIF-1alpha and HIF-1 activity in hypoxic cultured human cancer cells. Biochem Pharmacol. 2008; 75:1858-1867.

26. Roy A, Ganguly A, BoseDasgupta S, Das BB, Pal C, Jaisankar P and Majumder HK. Mitochondria-dependent reactive oxygen species-mediated programmed cell death induced by 3,3'-diindolylmethane through inhibition of F0F1-ATP synthase in unicellular protozoan parasite Leishmania donovani. Mol Pharmacol. 2008; 74:12921307.

27. Kandala PK and Srivastava SK. Regulation of macroautophagy in ovarian cancer cells in vitro and in vivo by controlling glucose regulatory protein 78 and AMPK. Oncotarget. 2012; 3:435-449.

28. Wong CP, Hsu A, Buchanan A, Palomera-Sanchez Z, Beaver 
LM, Houseman EA, Williams DE, Dashwood RH and Ho E. Effects of sulforaphane and 3,3'-diindolylmethane on genome-wide promoter methylation in normal prostate epithelial cells and prostate cancer cells. PLoS One. 2014; 9:e86787.

29. Schneider CA, Rasband WS and Eliceiri KW. NIH Image to ImageJ: 25 years of image analysis. Nat Methods. 2012; 9:671-675.

30. Guha R, Howard MT, Hutchison GR, Murray-Rust P, Rzepa $\mathrm{H}$, Steinbeck C, Wegner J and Willighagen EL. The Blue Obelisk-interoperability in chemical informatics. J Chem Inf Model. 2006; 46:991-998.

31. Morris GM, Huey R, Lindstrom W, Sanner MF, Belew RK, Goodsell DS and Olson AJ. AutoDock4 and AutoDockTools4: Automated docking with selective receptor flexibility. J Comput Chem. 2009; 30:2785-2791.

32. Berman HM, Westbrook J, Feng Z, Gilliland G, Bhat TN, Weissig H, Shindyalov IN and Bourne PE. The Protein Data Bank. Nucleic Acids Res. 2000; 28:235-242.

33. Hetenyi $\mathrm{C}$ and van der Spoel D. Efficient docking of peptides to proteins without prior knowledge of the binding site. Protein Sci. 2002; 11:1729-1737.

34. Lim SV, Rahman MB and Tejo BA. Structure-based and ligand-based virtual screening of novel methyltransferase inhibitors of the dengue virus. BMC Bioinformatics. 2011; 12 Suppl 13:S24.

35. Trott $\mathrm{O}$ and Olson AJ. AutoDock Vina: improving the speed and accuracy of docking with a new scoring function, efficient optimization, and multithreading. J Comput Chem. 2010; 31:455-461.

36. Ranjan N, Andreasen KF, Kumar S, Hyde-Volpe D and Arya DP. Aminoglycoside binding to Oxytricha nova telomeric DNA. Biochemistry. 2010; 49:9891-9903.

37. Wolber G and Langer T. LigandScout: 3-D pharmacophores derived from protein-bound ligands and their use as virtual screening filters. J Chem Inf Model. 2005; 45:160-169.

38. Durdagi S, Duff HJ and Noskov SY. Combined receptor and ligand-based approach to the universal pharmacophore model development for studies of drug blockade to the hERG1 pore domain. J Chem Inf Model. 2011; 51:463-474.

39. Mounir Z, Krishnamoorthy JL, Wang S, Papadopoulou B, Campbell S, Muller WJ, Hatzoglou M and Koromilas AE. Akt determines cell fate through inhibition of the PERKeIF2alpha phosphorylation pathway. Sci Signal. 2011; 4:ra62.

40. Rahman KW and Sarkar FH. Inhibition of nuclear translocation of nuclear factor-\{kappa $\}$ B contributes to 3,3'-diindolylmethane-induced apoptosis in breast cancer cells. Cancer Res. 2005; 65:364-371.

41. Huang X, Chen Y, Zhang H, Ma Q, Zhang YW and Xu H. Salubrinal attenuates beta-amyloid-induced neuronal death and microglial activation by inhibition of the NF-kappaB pathway. Neurobiol Aging. 2012; 33:1007 e1009-1017.

42. Kessel D. Protection of Bcl-2 by salubrinal. Biochem Biophys Res Commun. 2006; 346:1320-1323.

43. Ouyang DY, Xu LH, He XH, Zhang YT, Zeng LH, Cai JY and Ren S. Autophagy is differentially induced in prostate cancer LNCaP, DU145 and PC-3 cells via distinct splicing profiles of ATG5. Autophagy. 2013; 9:20-32.

44. Rokhlin OW, Taghiyev AF, Bayer KU, Bumcrot D, Koteliansk VE, Glover RA and Cohen MB. Calcium/ calmodulin-dependent kinase II plays an important role in prostate cancer cell survival. Cancer Biol Ther. 2007; 6:732-742.

45. Liu Y and Templeton DM. Initiation of caspase-independent death in mouse mesangial cells by $\mathrm{Cd} 2+$ : involvement of p38 kinase and CaMK-II. J Cell Physiol. 2008; 217:307318.

46. Timmins JM, Ozcan L, Seimon TA, Li G, Malagelada C, Backs J, Backs T, Bassel-Duby R, Olson EN, Anderson ME and Tabas I. Calcium/calmodulin-dependent protein kinase II links ER stress with Fas and mitochondrial apoptosis pathways. J Clin Invest. 2009; 119:2925-2941.

47. Mamaeva OA, Kim J, Feng G and McDonald JM. Calcium/ calmodulin-dependent kinase II regulates notch-1 signaling in prostate cancer cells. J Cell Biochem. 2009; 106:25-32. 